\title{
Coaching and Scouting: A managerial framework for Sports Development.
}

\author{
Hitesh Mangtani* \\ * Independent Researcher (Sports), Master of Business Administration (MBA) - Sports Management. \\ DOI: 10.29322/IJSRP.11.05.2021.p11321 \\ http://dx.doi.org/10.29322/IJSRP.11.05.2021.p11321
}

\begin{abstract}
Sport is a dynamic field where athletes have to frequently enhance their skills, tactics, techniques, training methodologies. The sports ecosystem itself is so vigorous in its true sense where administrators, managers, and policymakers have to be well informed of the latest sports market trends, so the industry or ecosystem in the respective regions is continuously evolving and challenging itself. Coaches and scouts are as critical as athletes at each stage of development hierarchy, so we are discussing a need of the hour implementation of a framework to be placed for scouts, coaches, administrators to be part of the budding system for enhancement of self-sustainability factor of sports development in the country from an administrative and managerial standpoint.
\end{abstract}

Index Terms- Sports, Development, Coaching, Scouting, Management Framework.

\section{INTRODUCTION}

As a society, we have so many things to talk about, worry little, and often forgot some of the most critical aspects (sports specific in this case) of acting and reacting as a community, irrespective of the region(s). One of the aspects that are overlooked, in Sports, as management of ecosystem per se, is the contribution of scouts or the scouting network we have in place, alongside the coaching framework ${ }^{(1)}$ the country generally has running for training, identifying, recognizing, developing and managing various critical nuances about and around the athletes - be it elite, youth, or junior categories respectively. Just so we are clear, in our mind, by a scouting and coaching framework (which generally is a strongly interconnected network of scouts and coaches), it is not a proposal of unlawful activities and processes. The true motive behind exploring these concepts and practices of scouting and coaching from a managerial point of view (as they are an integral part of the system), or as the title says it 'framework' is to learn what it takes to build a system to be able to support athlete identification, recognition and development opportunities at various levels of our society in different parts of the world.

We are living in a digital era, where things cannot go unnoticed, unheard, un-attended for a longer duration. Now the power is in the hands of people, the community. The very people we are trying to convince to get associate themselves with some form of physical activity or sporting discipline daily. It is in line with the idea to initiate, monitor, further re-iterate, and maintain the need to inspiring an active sporting culture within our communities and have an overall impact on the growth of a healthier society and as a Nation ${ }^{(2)}$. Coaches, Scouts, Trainers, Administrators associated with respective sport's governing bodies and NSFs at different stages in various levels of our societies (irrespective of the Nation), we are prone to be scrutinized in a manner which we potentially cannot fathom, and we do not wish to honestly. The coaches, scouts \& athlete management, or development specialists are assigned a job to identify, recognize, detect and develop the athlete(s), also termed as talent in many cases, whom we can further manage from a framework perspective. The framework will (for sure) differ based on 'n' number of parameters, evidently based on,

- Political, Legal and Legislative dynamics ${ }^{(3)}$ of each region, state/province, and the Nation,

- Democracy, Leadership (within the organization), and Governance ${ }^{(4)}$ of the bodies (sports in specific), or the NSFs responsible for decision making \& implementation, which further includes the availability and allocation of the following listed below at each level of the framework (already in place or part of the plan to be included),

- Infrastructure ${ }^{(5)}$ required for practice, participation, progression etc.,

- Sports Science Experts, Nutritionists,

$\circ$ Performance Analysts ${ }^{(6)}$ and Physiotherapists ${ }^{(7)}$,

O Other key personnel.

- Awareness, Recollection \& Acceptance of sporting discipline(s) in each region, state/province, and the Nation.

- Development and Management Professionals (sports specific) in each region, state/province and the Nation for financial viability, scheme/property ideation, and further progressive analysis \& proficient reporting.

- No. of partners/sponsors willing to be associated with development, promotion \& maximization of the impact of sports in the community in each region, state/province and the Nation. 


\section{OUR RESEARCh, COLLECTED INFORMATION \& IDEATION}

It is imperative to keep all the aspects of politics ${ }^{(3)}$, Leadership, Governance ${ }^{(4)}$, availability of resources, and awareness of sporting discipline(s) in mind before we move forward to plan, design, develop and implement, or deploy a framework in any region, state/province or nationwide. It is also critical for us to keep tracking the funds granted by the respective ministries, authorities, sport's governing bodies, or National Sports Federations (NSFs) to each other, or any other relevant organization/firm for development, enhancement, and progression of respective sporting discipline(s) in the region. This monitoring exercise (to track the financial capital induced) will help us catch sight of how the management framework for coaching, scouting, and training is being taken care of by the respective bodies in each region, state/province, and evidently in the Nation as a whole.

For this particular managerial framework, we are contemplating the financials of the Sports Authority of India (SAI), established by the Indian Ministry of Youth Affairs \& Sports (MYAS), to get a clear picture of the money spent in terms of the development of athletes via concentrating on National Coaching Camps (youth, junior, senior, etc.), Training Remunerations (Domestic \& International) and Coach \& Staffing Expenses (National \& Foreign) and Domestic \& International tournaments/events which adds-up to about ₹3523.7 Million (₹3.52 Billion) in 2019, an of average ₹146.8 Million (₹0.14 Billion) amongst 24 NSFs ${ }^{(8)}$ (Figure 1 in Millions, Figure 2 in Crore). However, as of $19^{\text {th }}$ April 2021, the total expenditure concerning National Coaching Camps (youth, junior, senior, etc.), Training Remunerations (Domestic \& International) and Coach \& Staffing Expenses (National \& Foreign), and Domestic \& International tournaments/events incurred by Sports Authority of India is close to ₹1743.86 Million (₹1.74 Billion) with an average of ₹93.26 Million amongst $20 \mathrm{NSFs}^{(9)}$ (Figure 3 in Millions, Figure 4 in Crore).

Taking into account the Long-Term Development ${ }^{(10)}$ of athletes ${ }^{(11)}$, potentially targeting their performance for the Olympic and Paralympic 2024 Games ${ }^{(12,13)}$ and 2028 Games ${ }^{(14,15)}$, recently the Swimming Federation of India (SFI) and the Ministry of Youth Affairs \& Sports - TOPS (Target Olympic Podium Scheme) Division agreed to bear the cost of ₹8.78 Lakhs (₹0.87 Million) for 6-days for professional/consultation charges, airfare, boarding \& lodging, visa and transport for Dr. Genadijus Sokolovas - a renowned Physiologist \& Sports Science expert ${ }^{(16)}$. Additionally, the Paralympic Committee of India (PCI) has partnered with the Small Industries Development Bank of India (SIDBI) to support their training with sports equipment, with financial assistance worth around ₹15 Lakhs (₹1.5 Million) in purchasing various sports equipment under their CSR initiative to boost para-athlete’s preparation for Tokyo 2020 Paralympic Games ${ }^{(17)}$.

All these decisions and activities prove the point of focusing and giving importance to having experts in the field of Sports, Physical Education, and Recreation activities, such as Coaches, Trainers, Athlete Managers, Development Officers, Strength \& Conditioning $(\mathrm{S} \& \mathrm{C})$ Experts, Masseurs with the provision of relevant resources at our disposal to help the ecosystem around and about athletes evolve, and flourish effectively and efficiently.

\section{OUR STUdies, FindingS \& SPORTS DEVELOPMENT FRAMEWORK}

Specifically, from an Indian sub-continent perspective, the Sports Ecosystem, which is apparently suffocated, with roots of politics ${ }^{(3)}$, hunger for power, and ideas for a democracy (where everyone is allowed to have the freedom to express themselves, a chance to showcase or further enhance their professional skills) but in reality, sporting disciplines have been discontented to the magnitude that its natural connection/originality with our sizeable society/societies have been completely stripped off and quote, "only amateur sports keep this organic connection to society" ${ }^{(18)}$.

Eventually, for all levels of our sports ecosystems to be kept alive to act as a link between building the national economy and its sports coaching \& scouting management architecture, also termed as the framework (specific to sports). We as a group of sports management and development specialists need to take the responsibility and articulate what does it take (in reality) to plan, build, implement, and further maintain the fully functional framework of Sports in the country, also known as The Business of Sports ${ }^{(19)}$. The framework will be specific to the Indian sub-continent where the growth in terms of awareness, acceptance, recognition of Sports has to be substantial, with the potential of being the industry leaders if we take calculated and constructive decisions to further our goals, objectives, and KRAs. Each parameter will have to be enhanced and regularly monitored for our coaching and scouting network. To do so, we might have to look at the development process with a Bottom-Up-Approach, instead of Top-Down-Approach ${ }^{(20)}$. (Figure 5).

We do have a twist in the story, as we are about to discover as we go along further enhancing our framework with a possibility of implementing it in the real world (i.e., apply this framework in association with NSFs in India). As of today, the Ministry of Youth Affairs \& Sports, the Sports Authority of India, State Associations, and respective heads of NSF's ${ }^{(8,9)}$ (President, Secretary, and Committee/Department Heads) are responsible for making decisions. The associates/assistants are required to implement these decisions in their respective regions, districts, states/provinces, which a typical and traditional form of management ${ }^{(20)}$ and might be the effective one. But, if we (as a Nation) want to develop and inherit a sporting culture in the South Asian sub-continent, we should look forward to thinking a bit differently since the wind of cultural change ${ }^{(21)}$ (specific to sports development) from the Indian perspective is blowing in the right direction. 


\section{A. Putting a few bits and pieces together}

Firstly, we should be looking forward to supporting our coaches and scouts of different sporting disciplines, primarily From-The-Top (Figure 5), i.e., in terms of support from the management with up-to-date coaching and counseling methodologies. The reason being, coaches and scouts are the closest to athletes after parents or guardians. It also means availing services of foreign experts as advisors to oversee the implementation and monitoring process of the particular sporting dimension. Secondly, From-The-Bottom (Figure 5), i.e., by providing resources concerning accustomed, trained, and proficient people who would act as regional managers and assistants responsible for delivering, sharing, and maintaining the ecosystem in respective communities, districts, regions, states/provinces.

To successfully evolve as a system, while being able to take effective decisions by utilizing available resources efficiently, the sports ecosystem decision makers, administrators, managers in coordination with coaches, trainers, and respective sports-science experts have to work in unison to have a mix of both, the bottoms-up-approach ${ }^{(20)}$ (Figure 5) where coaches, trainers, sports-science experts (Figure 8-11) will be collecting data, developing insights and reporting to the regional heads (Figure 6, Figure 7), who will further collate the facts \& figures to be able to present the overall picture, story and progress of each region assigned to them, as well as the top-down-approach ${ }^{(20)}$ (Figure 5) where the high level executives (specific to India in this case) such as MYAS, SAI, NSFs Heads ${ }^{(8,9)}$ will be looking at the data, insights and growth of respective sporting disciplines in the region to come up with policies, strategies for partnerships \& sponsorship activations to further enhance the acceptance of individual sporting disciplines (Figure 6, Figure 7) in the respective communities, districts, regions, states/provinces. It's more like a $360^{\circ}$ Performance Review System/Mechanism ${ }^{(22)}$. It is further applicable for stadium/infrastructure/facility evaluation and process enhancement ${ }^{(23)}$.

The high-level executives (specific to India in this case) such as MYAS, SAI, NSFs Heads ${ }^{\left({ }^{8,9)}\right.}$ will further be involved with the regional authorities (specific to Indian sub-continent) of all respective Indian States \& Union Territories (UT) ${ }^{(24)}$, and further drive it down to all the districts ${ }^{(25)}$ of these States \& Union Territories (UT) ${ }^{(24)}$ in India. For instance, the state of Uttar Pradesh (UP) has 75districts, and Madhya Pradesh (MP) has 52-districts under their umbrella whereas, and Jammu \& Kashmir (J\&K) Union Territory (UT) have 20-districts under their belt to further their effort for the development of Sports in the respective communities. Ironically, under the National Sports Development Fund (NSDF) initiative established in 1998 under the Charitable Endowments Act 1890 and further notified by the Government of India in November 1998, a sum of ₹303.87 Crore (₹3038.7 Million | ₹3.03 Billion) has been utilized in different capacities (as of 30.11.2019) such as, for giving financial assistance to 389 Sports Persons (86 athletes currently under TOPS for Tokyo 2020 Games), Sports Organizations/NSFs ${ }^{(8,9)}$, and other organization or institutions for development, and enhancement of new/existing infrastructure and/or sports facilities ${ }^{(26)}$. The most interesting one among all that might sound interesting (sarcastically) is the National Information Centre (NIC) Services Inc. for Development of Sports Software, estimated to cost around ₹74.3 Thousand (₹0.743 Lakh) ${ }^{(26)}$.

Recently, Target Olympic Podium Scheme (TOPS) division approved the proposal to render services of a sports psychologist for better preparation ahead of the Tokyo 2020 targeting two Olympic-bound Indian shooters. The expenses are estimated to be ₹2.9 Million (₹29 Lakh) apart from ₹6.83 Million (₹68.3 Lakhs) for Angad regarding international training, ammunition, and out of pocket allowance, ₹2.149 Million (₹21.49 Lakh) for Manu for ammunition, equipment, and out of pocket allowance, sanctioned early ${ }^{(27)}$. Monetization of such activities in any Sports Ecosystem is critical. We need to enable a self-sustainable framework with the availability of financial capital, to manage sports-specific activities. It further measures the overall success or failure of the tournament/championships and the organization. Partnerships and sponsorships ${ }^{(28)}$ have a deeper connection with sports in different parts of the world, through which athlete development ${ }^{(29)}$ and participation are encouraged. It further drives us to grasp executive business operations in the Sports Industry, which in 2019 - estimated to be $\$ 480$ to $\$ 620$ Billion with a 5.9\% CAGR (globally) ${ }^{(30)}$.

Indian Sports Sponsorship Market, reached ₹9000+ Crore mark (growth rate 17\%) in $2019^{(3 l)}$ as per ESP Properties - GroupM Report titled, Sporting Nation in Making VII. According to the report, athlete endorsements touched ₹537 Crore (₹77 Million) mark with a growth rate of $11 \%$ compared to 2018 numbers of ₹ 482 Crore (₹71 Million) ${ }^{(31)}$. Female athletes led the non-cricketing athlete endorsement space in 2019 with 101 brands (overall non-cricketing endorsement by brands) compared to 86 brands who endorsed non-cricketing athletes in $2018^{(31)}$.

\section{B. Detailed functioning of the Coaching and Scouting Development Framework}

How do we further link this industry growth (in terms of sheer numbers) to the functioning of our coaching and scouting framework? Can this potentially result in further enhancement and recognition of sports in the Indian sub-continent? World Health Organization (WHO) has officially acknowledged the importance of Health-Enhancing Physical Activity (HEPA) ${ }^{(32)}$ promotional policies \& activities in the communities in coordination with local government such as the districts, regions, states/provinces ${ }^{(32)}$. Although, COVID-19 situation dis-functioning \& improper management primarily involving $\mathrm{WHO}{ }^{(33)}$, are a bit of concern and a bitter pill to swallow for everyone who constantly follows the situation to guess the political drama ${ }^{(34)}$ that's being played about and around this pandemic. Furthermore, we are looking at a far more complicated or complex style of development and management structure. We will have to ensure that the talent/athlete identification, recognition, and development processes along with the infrastructure evaluation remains intact with all necessary arrangements promised by the organizers (from a healthcare perspective), such as strictly 
following the bio-bubble protocols, vaccination, quarantine timelines and other preventive measures at each level, i.e., community, district, region, states/provinces. Vaccination, however, is the elephant in the room. Not just in terms of availability - on a country-tocountry basis, but also about efficacy and reliability. A hot topic for sports discussions and debates if we carefully study the political dominance \& geopolitical scenario(s) associated with the vaccination program(s).

The process of planning, development, management, and implementation becomes effortless if we realize that we need help. Why not just ask for it? Considering our efforts to discuss the formulation, development, and noticeable implementation of this coaching and scouting framework for further development, or enhancement of sporting disciplines in our respective regions, it gets easier with all the necessary help as we go along working together on the project collectively. Job descriptions for each position of this coaching and scouting framework are described purposely, after careful alignment with the overall goals and objectives of the organization, i.e., the NSFs in this case (Figure 6-12). A statement that might conclude this thought is that an athlete is never alone. He/she/they always have a team going to work with them. This team consists of their partners or guardians, their coaches, the support staff, trainers, sports administrators \& governing bodies, management professionals or agents, sponsors, partners. Every member is equally responsible for the success or failure, or whatever that comes in the way. Social media platforms in this digitized era such as Twitter ${ }^{(35)}$, Instagram, Facebook, YouTube, and LinkedIn can prove to be valuable when it comes to the offline analysis of the athlete(s) or team(s) performance ${ }^{(36)}$ in a nutshell (excluding the psychological, physical \& behavioral factors). It supports the plan to initiate a viable and analytical interaction with the fans \& followers of the sport(s).

This framework for coaching and scouting, specifically from a managerial standpoint, is flexible and can be upgraded for any of the NSFs working in different corners of the world (we are considering the implementation process for the Indian sub-continent), based on tactical knowledge, technical studies, extensive market research, and region-specific surveys conducted by the departments. The framework is adjustable and can further be re-designed for an individual or a team sport after considering the hierarchical changes which will have to be considered as part of the re-iteration process. For instance, the federations of Squash, Table Tennis, Tennis, Cycling, Swimming, Fencing, Rowing, Rugby, Archery, Boxing, Basketball, Volleyball, Handball, Equestrian, etc., in India can potentially benefit from this implementation with one specific condition, i.e., to keep aside the politically inclined and ignited motives, or aspirations away from every stage.

Our history speaks for itself, and considering the Indian geopolitical scenario, it is practically impossible to pursue a total disassociation between politics and sports. Therefore, a relatively measurable parameter for political involvement has to be included in the schemes, initiatives, and respective programs to ensure an unbiased environment, and the cultural norm is encouraged and practiced by each member in the sports ecosystem. The proof of the pudding is in the eating (37). We will eventually find out the magnitude of distractive political involvement we should be swiping out of the evolving India sports ecosystem, in the coming years.

Implementation of such methodologies and frameworks is easier said than done. Considering the potential demand, recognition, and growth of a particular sports discipline in the country, and also based on a survey conducted by the NSFs about the communities, district, region, state/province-specific growth, and its promotional aspects, the roles can be further be exclusively designed for Men and Women Team's to measure the overall success, or failure of the schemes, and programs. While we keep that in mind, let us start with our first (1st) position in the hierarchy, i.e., Coach Advisor who can be a foreigner or a local individual (Figure 6), depending on the funding opportunities, experience, and specific requirements of the NSF(s).

- He or She will play a leading role (pre-dominantly for the elite category) in helping that particular NSFs to decide,

- On-ground \& game specific coaching strategies along with tactical best practices,

- Athlete Identification, Recognition and Development Strategies,

- Schemes, Initiatives, and Programs strategic alignment for grassroots development,

○ Design and implement the Scouting \& High-Performance Management (HPM) framework.

- He or She will be responsible for closely monitoring the progress of a particular sporting discipline's,

- Training \& Coaching structural hierarchy,

- Scouting \& High-performance process (primarily development, implementation \& maintenance),

- Athlete Identification, Recognition \& Development (i.e., schemes or initiatives or programs), and respective KPI's,

- Coaches Training \& Development (i.e., schemes or initiatives or programs), and

- Share relevant information for further enhancement of the sporting discipline in India.

- He or She will be the point-of-contact (POC) for all International tournaments recognized and approved by the respective International Sports Federation (ISF) such as World Championship, World Cup, Commonwealth Games, Asian Games, Olympic and Paralympic Games.

- He or She will periodically (more likely) share knowledge and also interact with Coaches (Elite \& Junior), Athletes (Elite \& Junior), and Support Staff on the coaching tactics and approach \& requirements for each game (with specifics). 
The second $\left(2^{\text {nd }}\right)$ position in the hierarchy, i.e., Coach Manager (Elite), who will be a local individual (Figure 6),

- He or She will be reporting directly to the Coach Advisor.

- He or She will be responsible for working with elite players (only) on,

$\circ$ On-ground physical fitness and training modules,

○ Conceptualizing, planning \& analyzing game-specific strategies (before \& after the game),

$\circ$ Travel for respective tournaments (as per NSFs policies).

- He or She will closely work with the NSFs Administrative Team, Coach Advisor, Coaching Committee, Scouting and Development departments, and Coach Training Program teams for assistance on,

- Skill development (both technical and tactical),

- Implementing a strong foundation of athlete Identification, Recognition, and Development concepts \& practices,

- Schemes/initiatives/programs initiation, development, and monitoring, and

- Technical and tactical knowledge sharing initiatives as per policies and NSF protocols.

- He or She will work with respective regional heads to coordinate coaching requirements for elite athletes, based on the schedule for all tournaments/events recognized and approved by the NSFs, and ISFs.

- He or She will be responsible for,

- Sharing administrative knowledge,

- Working with respective coaches and elite players on court,

- Coordinate with HPM, Development \& Scouting departments for overall nourishment of the 'sport' (only elite's) while targeting podium positions in all yearly tournaments scheduled, both Nationally \& Internationally.

- He or She will be responsible for monitoring and keeping track of,

- Performances (technically),

$\circ$ Injuries and Recovery processes,

- Progress reports of all elite players who represent the NSFs, and the Nation (including those who would soon).

- He or She will play a key role in helping players transition from the Senior level to the Elite level.

- He or She will be the point-of-contact (POC) for Regional Coaches (Elite) and responsible for performance mapping \& further alignment of their goals \& objectives, and overall Mission, Vision, and Core Value of the respective NSF.

The third ( $\left.3^{\text {rd }}\right)$ position in the hierarchy, i.e., Coach Manager (Junior), who will be a local individual (Figure 6),

- He or She will be reporting directly to the Coach Advisor.

- He or She will be responsible for working with junior/sub-junior players (only) on,

$\circ$ On-ground physical fitness and training modules,

- Conceptualizing, planning \& analyzing game-specific strategies (before \& after the game),

- Travel for respective tournaments (as per NSFs policies).

- He or She will closely work with the NSFs Administrative Team, Coach Advisor, Coaching Committee, Scouting and Development departments, and Coach Training Program teams for assistance on,

○ Skill development (both technical and tactical),

- Implementing a strong foundation of athlete Identification, Recognition, and Development concepts \& practices,

- Schemes/initiatives/programs initiation, development, and monitoring, and

- Technical and tactical knowledge sharing initiatives as per policies and NSF protocols.

- He or She will work with respective regional heads to coordinate coaching requirements for junior/sub-junior athletes, based on the schedule for all tournaments/events recognized and approved by the NSFs, and ISFs.

- He or She will be responsible for,

- Sharing administrative knowledge,

- Working with respective coaches and junior/sub-junior players on court,

- Coordinate with HPM, Development and Scouting departments for overall nourishment of the 'sport' (only junior/sub-junior) while targeting podium positions in yearly tournaments, both Nationally \& Internationally.

- He or She will be responsible for monitoring and keeping track of,

○ Performances (technically),

- Injuries and Recovery processes,

- Progress reports of all junior players who represent the NSFs, and the Nation (including those who would soon).

- He or She will play a key role in helping players transition from the Senior level to the junior/sub-junior level.

- He or She will be the point-of-contact (POC) for Regional Coaches (junior/sub-junior) and responsible for performance mapping \& further alignment of their goals \& objectives, and overall Mission, Vision, and Core Value of the respective NSF. 
The fourth $\left(4^{\text {th }}\right)$ position in the hierarchy, i.e., Coach Training Program Manager (Figure 6),

- He or She will be reporting directly to the Coach Advisor.

- He or She will be working with NSFs Administrative Team, Coach Advisor, Coach Manager (both Elite \& Junior) for,

$\circ$ Ideation and Conceptualization of coach development schemes/initiatives/programs,

- Planning and implementation of respective schemes or programs in different regions for coach development.

- He or She will be responsible for procurement, management, and distribution of data, information, content, and certifications required for the proficiency of coaches in the respective regions as per the development policy set by NSFs and ISFs.

- He or She will play a helping hand in,

- Knowledge sharing via schemes/initiatives, or programs for enhancing coaching and scouting techniques,

- Marketing, Promotion, and Branding of Coach Training schemes/initiatives/programs,

- Implementation of schemes/initiatives/programs for teaching Athlete Identification, Recognition and Development concepts, practices, and methodologies via

- Case studies,

- White Paper,

- Research articles, and

- NSFs Corporate presentations (primarily designed for other sporting disciplines).

- He or She will play a significant role in,

$\circ$ High-Performance Framework planning, designing, and monitoring,

○ Transitioning methods from being an athlete - to being a coach.

$\circ$ Managing transitions involving certifications, training categories required as part of the framework,

- He or She will responsible for,

○ Tracking coaches' performances (on \& off the field),

○ Monitoring the progress of individuals under the Coach Training Program (at each level).

- He or She will be responsible for regular or more frequent interactions with the NSFs Administrative Team, Coach Advisor, and the Coaching and Scouting departments for amendments and further enhancements of the initiatives, or program in different regions, societies, and communities of the Nation.

- He or She will be significantly responsible for inculcating the Vision, Mission, and Core Values of the NSF via Coach Training schemes/initiatives or programs as the Program Head.

The fifth $\left(5^{\text {th }}\right) \&$ sixth $\left(6^{\text {th }}\right)$ positions, i.e., Regional Head Coach (Elite) and Regional Head Coach (Junior) respectively (Figure 8),

- He or She will be reporting directly to the Coach Manager - Elite and Junior/Sub-Junior, respectively.

- He or She will be responsible for actual 'regional' implementation of the,

$\circ$ On-ground physical fitness and training modules,

- Game-specific strategies (before \& after the game),

- Athlete Identification, Recognition and scouting schemes/initiatives, or programs and opportunities,

- High-Performance best practices designed by Coach Advisor, Coach Manager (Elite \& Junior) in consultation with NSFs Administrative Team, Coach Training Program Manager, and the Athlete Identification/Scouting Team.

- He or She will be responsible for

- Tracking athletes/talents performances,

- Maintaining a database of all registered potential prospects/athletes, and

- Sharing the data/information/content, or statistics related to all respective athletes in the region with the Athlete Identification, and Scouting Team, Coach Managers (Elite \& Junior/Sub-Junior) for further review \& analysis.

- He or She will be accountable to,

- Arrange, Coordinate, and successfully deliver training camps \& other initiatives in discussion with Coach Managers (Elite \& Junior respectively) in their respective regions, in coordination with the Development Team/Managers,

- Organize the Coach Advisor's visits and sessions depending on schedule declared by the NSFs.

- He or She will play a significant role in preparing athletes for regional, national, and international tournaments in frequent discussion with respective Coach Managers (both Elite \& Junior respectively) as per the NSFs \& ISFs schedule.

- He or She will be strictly responsible for sharing candid feedback with the NSFs Administrative Team, Coach Managers (Elite \& Junior/Sub-Junior respectively), Athlete Identification/Scouting Departments about,

$\circ$ Ground realities regarding the initiatives designed \& approved by the NSF,

- Adaptive, effective and self-sustainable measures, or suggestions to be taken for amendment of these initiatives indiscussion with Coach Advisor, Coach Managers (Elite \& Junior/Sub-Junior), and Development departments.

The seventh $\left(7^{\text {th }}\right)$ position in the hierarchy, i.e., Regional Program Head (Coach Training) who will be a local individual (Figure 8), 
- He or She will be reporting directly to the Coach Training Program Manager.

- He or She will be responsible for actual 'regional' implementation of the,

- Coach Training Program development and training schemes/initiatives/programs designed by NSFs.

- He or She will be responsible for coordinating, implementation \& monitoring of Coach Training program modules for,

- Elite Level,

$\circ$ Junior Level and,

○ Sub-Junior Level.

- He or She will be responsible for coordinating, procurement, distribution \& management of,

- Data, information, content, or statistical analysis related to certifications required for the proficiency of coaches in respective regions as per the coach development policy of the NSF.

- He or She will be responsible for,

- Delivering knowledge sharing sessions to coaches of different levels,

- Content creation, distribution and management of all Athlete-to-Coach transitions.

- Enable marketing, promotion, and branding of opportunities for the Coach Training schemes, or programs.

- He or She will play a definitive role in pathway design and management of athletes transitioning from players to coaches.

- He or She will be responsible for,

- Tracking of coaches' performances (on \& off the field),

- Managing as well as Monitoring transitions (between different levels),

- Coach Training certification/proficiency levels, or

- Athlete-To-Coach certification/proficiency levels,

- He or She will be responsible to regularly interact (more frequently) with the Coach Training Program Manager for any update on amendments \& enhancements of the initiatives in different regions, societies, and communities of the Nation.

- He or She will be held accountable to inculcate the Vision, Mission, and Core Values of the NSF via Coach Training schemes/initiatives or programs designed and approved by the NSF.

The eight (8th) \& ninth (9th) positions in the hierarchy, i.e., Assistant Coach (Elite \& Junior) who will be an Indian (Figure 9-10),

- He or She will be reporting directly to the Regional Head Coach - Elite \& Junior/Sub-Junior,

- He or She will be responsible for assisting the Regional Head Coach - Elite \& Junior respectively in actual implementation \& management of,

$\circ$ On-ground physical fitness and training modules,

- Conceptualizing, planning \& analyzing game-specific strategies (before \& after the game),

- Travel with players for respective tournaments, if necessary (as per NSFs policies).

- He or She will be responsible for,

- Encouraging New entrants - elite \& junior, registration with regional academies \& centers accredited by NSFs,

- Create, collate \& maintain a detailed digital record of the,

- Family/Parents/Guardian details, and their contact details,

- Schools \& Higher education details, as applicable,

- Fitness test results, and Medical history,

- NSFs certified events/tournaments performances \& statistics, etc.

- He or She will be responsible for tracking, monitoring \& suggests potential changes for,

- Performance enhancement,

- Performance mapping \& statistical review under the supervision of Regional Head Coach,

- Suggest \& implement advanced coaching techniques under the supervision of the Regional Head Coach.

- He or She will be responsible for sharing regular (more often frequent) feedbacks \& any relevant/important information with the Regional Coach (Elite \& Junior respectively), Development Team, Coach Training Program Team.

- He or She will be responsible for track, monitor \& help in the progress of athletes transitioning from different levels,

- Develop \& maintain profiles of all athletes registered/potential talents within the region.

- He or She will be tasked to ensure that high-performance framework directives are inculcated in the training sessions for progression and timely transitioning,

- He or She will be the VVIP's to groom athletes (Elite \& Junior/Sub-Junior) and ensure the right set of skills, tactics, and psychological aspects are shared with young athletes.

The tenth $\left(10^{\text {th }}\right)$ position in the hierarchy, is Assistant Program Manager (Coach Training) who will be a local individual (Figure 11), 
- He or She will be responsible for assisting the Regional Program Head (Coach Training) for actual implementation, monitoring \& effective management of Coach Training Programs, or Initiatives by,

- Conducting training camps for coach training (both on-the-field \& classroom sessions) in various regions of India under the supervision of Regional Program Manager,

- Preparing coaching content for on-the-field work \& off-the-field sessions considering athletes of all respective age groups to ensure enough exposure to the ground reality of work in the Sports ecosystem.

- He or She will be responsible for,

$\circ \quad$ Registration of new and existing coaches.

- Collect, collate, maintain \& manage a detailed digital database of,

- Registered coaches within the regional academies \& coaching centers accredited by NSFs and ISFs,

- Coach performance enhancement tracking \& assessment results,

- He or She will be responsible for regular feedbacks and share relevant/important information with the Regional Program Head (Coach Training).

- He or She will be responsible for helping in the progression of coaches transitioning from different levels \& managing change in training sessions will be a critical part of their job on the court.

- He or She will be responsible for track, monitor \& help in the progress of coaches transitioning from different levels,

$\circ$ Develop \& maintain profiles of all coaches registered/potential talents within the region.

- He or She will be responsible for ensuring high-performance initiatives directed by NSFs, and ISFs get inculcated in the training sessions for progression \& higher timely transitioning.

- He or She will be the VIP to groom coaches \& ensure that the right set of skills, tactics \& psychological attributes are shared.

The hierarchy also has National Development Manager (NDM) as part of the process who will be a local individual (Figure 7),

- He or She will be working hand-in-hand with the Coach Advisor, NSFs Administration Team, Finance Department, Marketing \& Promotions Department, Public Relations (PR) Department, and will report to the Executive Committee,

- He or She will be responsible for,

$\circ$ Identifying the Key Research Area's (KRA's) for development and enhancement of the sporting discipline,

- Recognition of the Key Performance Indicators (KPI's) for effective \& efficient evaluation of the process, practices $\&$ methods, for the overall development of the sports and the administrative ecosystem,

○ Developing the Strategic Plan of the NSFs by scrutinizing all relevant \& available details such as,

- Geopolitical/Diplomatic scenario of the country, and each community, district, region, state/province,

- Financial/Economic situation of the Nation, ISFs, and more importantly the NSF itself,

- Legal guidelines and governing outlines put in place by the ministry and/or governing bodies.

- Managing, Maintaining, and Monitoring compliance with the constitutional development (in line with ISF \& NSF) of sporting discipline(s) within the country.

- He or She will be responsible for,

- Initiate marketing, promotions \& branding of the NSF's schemes/initiatives/programs throughout the country, i.e., community, district, region, state/province, in consultation with the Finance, Marketing, and PR departments,

- Significantly increasing the focus on participation, pre-dominantly in the grassroots for,

- Acceptance and recognition of sports (particular sporting discipline),

- Availability of equipment's, infrastructure, human resource (includes administrative staff),

- He or She will play a leading role to intellectualize the schemes/initiatives, or programs in terms of,

○ Budgeting \& financial capital requirements (e.g., National \& International Tournaments, Coaching Sessions, etc.),

- Scheduling of events in a year in coordination with ISFs, Governing Bodies, and State Associations/Federations,

- He or She will be critically responsible for closely managing,

- Sports specific sponsorship contracts/deals/MOUs for further enrichment of the sport in the country,

- Monitor region-specific sponsorship arrangements to balance the operations of sports ecosystem, while aiming for holistic development of the sport and generate substantial revenue for a self-sustaining ecosystem.

- He or She will be working hand-in-hand for,

- Identification, Recognition, and Development of athletes, and 1-on-1 goals and objectives mapping,

- Coach Training \& Development (i.e., schemes or initiatives or programs), and

$\circ \quad$ Sharing relevant information sharing for enhancement of the sport in the Nation.

- He or She will be the point-of-contact (POC) and the face of NSF with respective foreign/national representation.

- He or She will periodically interact \& accept genuine feedback from the Coaches (Elite \& Junior), Athletes (Elite \& Junior), Support Staff, Coaching \& Scouting departments on specific tactical/technical approaches and relevant requirements.

The hierarchy also has Regional Development Officer as part of the process who will be a local individual (Figure 12), 
- He or She will be working hand-in-hand with the National Development Manager, NSFs Finance Department, Marketing-PR Department, and Regional Head Coach (Elite \& Junior/Sub-Junior), Regional Program Head (Coach Training),

- He or She will be responsible for,

○ Identifying, re-iterating \& implementing region-specific KRAs for sports development,

- Implementation and monitoring of the region-specific KPIs for effective \& efficient evaluation of the process, practices \& methods, as described by the Development department.

- Implementation \& constant monitoring of directives as per the NSF's strategic plan while considering,

- Geopolitical/Diplomatic scenario of each community, district, region, state/province.

- Financial/Economic situation of the Nation, NSFs, Governing body \& the regional office itself,

- Legal guidelines and governing outlines put in place by the respective ministries and/or governing bodies,

- Managing, Maintaining, and Monitoring compliance with the Constitution of the ISF \& NSF within the region(s).

- He or She will be responsible for,

- Marketing, promotions \& branding of the NSF's schemes/initiatives/programs throughout the community, district, region, state/province in consultation with the National Development Manager \& Marketing-PR departments.

- Ensure there is an actual increase in the focus on participation, specifically the grassroots concerning,

- Acceptance and recognition of the sport (particular sporting discipline),

- Availability of equipment's, infrastructure, human resource (includes administrative staff),

- He or She will intellectualize the schemes/programs under the National Development Manager in terms of,

- Budgeting \& financial capital requirements (e.g., National \& International Tournaments, Coaching Sessions, etc.),

- Scheduling of events in a year in coordination with ISFs, Governing Bodies, and State Associations/Federations,

- He or She will be critically responsible for closely directing \& preparing,

- Sports specific sponsorship contracts/deals, or MOUs for further enrichment of the sport in respective regions,

- Implement region-specific sponsorship arrangements to balance the framework, while aiming for holistic development of the sport and generate substantial revenue for a self-sustaining ecosystem.

- He or She will be working hand-in-hand for,

$\circ \quad$ Athlete specific 1-on-1 goals \& objectives setting as well as monitoring,

○ Actual implementation and supervision of Coaches Training \& Development, and

0 sharing relevant information critical for further enhancement of the sport in respective region(s).

- He or She will be the point-of-contact (POC) and the face of NSF for regional representation for all tournaments such as National/International championships, regional qualifiers, and sub-divisional participating events.

- He or She will constantly interact \& accept genuine feedback from the Coaches (Elite \& Junior), Athletes (Elite \& Junior), Support Staff, Coaching and Scouting departments on specific tactical/technical approaches and relevant requirements.

The hierarchy also has Assistant Development Officer as part of the process who will be a local individual (Figure 13),

- He or She will be working hand-in-hand with the Regional Development Officer, Marketing, PR, Coaching \& Scouting departments, and Regional Head Coach (Elite \& Junior/Sub-Junior), Regional Program Head (Coach Training).

- He or She will be responsible for,

○ Implementation of regional \& community specific KRA's for development of the respective sport,

- Monitor region, and community-specific KPIs for tactful evaluation of the processes, and methods as per discussion with the National and Regional development authorities.

- Application of directives as per the NSF's strategic plan while considering,

- Geopolitical/Diplomatic scenario of each community, district, region, state/province.

- Financial/Economic situation of the Nation, NSFs, Governing body \& the regional office itself,

- Legal guidelines and governing outlines put in place by the respective ministries and/or governing bodies,

$\circ$ Manage and maintain compliance with the Constitution of the ISF \& NSF within the region(s).

- He or She will be responsible for,

- Marketing and promotions of the NSF's schemes/initiatives/programs throughout the community, district, region in consultation with the Regional Development Officer \& Marketing-PR departments.

- Ensure there is an actual increase in the focus on participation, specifically the grassroots concerning,

- Acceptance and recognition of the sport (particular sporting discipline),

- Availability of equipment's, infrastructure, human resource (includes administrative staff),

- He or She will conceptualization the schemes/initiatives/programs under the Regional Development Officer in terms of,

- Budgeting \& financial capital requirements (e.g., National \& International Tournaments, Coaching Sessions).

- Scheduling of events in a year in coordination with ISFs, Governing Bodies, and State Associations/Federations,

- He or She will be critically responsible for closely directing \& preparing,

- Sports specific sponsorship contracts, or MOUs for further enrichment of sports in the region \& communities, 
- Implement community-specific sponsorship arrangements to balance the framework, while aiming for holistic development of the sport and generate substantial revenue for a self-sustaining ecosystem.

- He or She will be critically responsible for success/failure of,

○ Athlete specific 1-on-1 goals \& objectives setting as well as monitoring,

○ Actual implementation and supervision of Coaches Training \& Development, and

- Share relevant information critical for further enhancement of the sport in respective region(s).

- He or She will be the point-of-contact (POC), and the face of NSF with respective community representation for all tournaments such as National/International championships, regional qualifiers, and sub-divisional participating events, etc.

- He or She will constantly interact \& accept genuine feedback from the Coaches (Elite \& Junior), Athletes (Elite \& Junior), Support Staff, Coaching and Scouting departments on specific tactical/technical approaches and relevant requirements.

These are just a few activities and responsibilities each member of the hierarchy would be responsible for but, the number of activities and responsibilities assigned significantly differs in terms of on-ground reality, as it totally depends upon the bench strength of the organization, i.e., the employment capacity, or existing employee base of the NSF (not just in terms of numbers of employee's, but substantially the skillfulness, resourcefulness, knowledge and understanding level of the employees). Financial stability, revenue generation capacity, and recognition of the NSFs (both legal \& consumer awareness), and current sponsors on-board are also some of the key factors which directly/indirectly affect the effectiveness and efficiency of day-to-day operations of the NSF (specific to India in this case). Eventually, we will have to realize - and we must do (sooner or later) that all reforms, or changes, or innovations, or encouragements are as good as the intentions of those who are planning, designing, implementing, and maintaining them ${ }^{(38)}$.

To further manage the implementation of the Coaching and Scouting developmental framework (specific to India in this case), we will further categorize the Indian states and union territories into Regions (R), and further sub-categorized into Clusters (C). These clusters (C) will have multiple Divisions (D) based on existing management and structural hierarchy (Figure 14), or relevant system put in place by the NSFs, in agreement \& discussion with governing bodies and respective state associations/federations. For example, Madhya Pradesh (MP) for this framework weighed up under Region-3 (R3) | Cluster-2 (C2). Furthermore, Madhya Pradesh has 52 districts, therefore within Region-3 (R3) | Cluster-2 (C2), we will have eight (8) Divisions (D) as follows, Bhopal, Ujjain, Gwalior, Indore, Hoshangabad, Sagar, Jabalpur (Figure 16). Each division will be responsibly managing and supervising the operations of 7-8 sub-divisions, such as Raisen, Ratlam, Shivpuri, Dewas, Betul, Rewa, Katni, respectively (Figure 16). (Figure 16).

An identical process needs to be designed (actually has to be) for all other respective Regions (R), Clusters (C) such as Ladakh, Chandigarh, Sikkim, Manipur, Daman and Diu, Jharkhand, Telangana, Kerala, and Divisions (D) such as Kargil, Doda, Gangtok, Namchi, Bishnupur, Chandel, Jamshedpur, Ranchi, Hyderabad, Siddipet, Kottayam, Palakkad, and so on. Now that we have carefully and strategically discussed the implementation process and hierarchy of coaching in the Indian sub-continent, we will also be giving equal importance and focus on ideation \& strategic implementation by having a structured hierarchy and processes for scouting (38) of talented athletes of all age groups, in India.

To do so, we will have a National Scout (Figure 14) who will be well informed and educated about tactical, technical, physiological, psychological, and developmental aspects of Sports, Nationally \& Internationally.

- He or She will play a leading role in,

- Designing programs or initiatives to enable \& create a platform for athletes to show their talent in consultation with the Marketing \& PR department, Coaching Department \& Development Department.

- Segregation \& selection of prospects/talents/athletes who will represent the sport ${ }^{(38)}$, the NSFs and the Nation,

$\circ$ Designing scouting framework in association with Coach Advisor.

- He or She will be responsible for closely monitoring the integration progress of,

- Scouting structural hierarchy,

- Parameters for Identification, Detection, and Recognition in line with the NSF's KRAs and KPIs,

- Information sharing of potential prospects/talents/athletes with the Coach Advisor, National Development Manager.

- He or She will keep track of interactions with Parents ${ }^{(39)}$, Coaches, Athletes, Trainers about the prospects/athletes..

- He or She will be responsible for final selection of athletes, and their contract evaluation in discussion with Coaches, Support Staff, Development Team \& NSF Committees who would represent the Nation based on ${ }^{(39)}$ reports shared by the Scouting Program Manager (Elite \& Junior Categories), Talent Verification \& Coaching Departments.

- He or She will keep the NSFs up-to-date with the Scouting norms \& strategic developments for further innovation.

- He or She will be the point-of-contact (POC) and look towards all scouting-related activities in the country.

The hierarchy also has a Scouting Program Manager (Elite Category) part of the process who will be an Indian citizen (Figure 14), 
- He or She will play a leading role,

- To ensure implementation of scouting programs/schemes or initiatives for Identification, Detection, and Recognition of potential talents/athletes for elite categories, in association with Development \& Coaching Departments,

- Segregation of elite prospects/talents/athletes who have potential to represent the sport ${ }^{(38)}$ and the Nation,

$\circ$ Monitor Scouting Framework (Elite) implementation with National Scout, Coach Advisor \& NDM (Figure 7).

- He or She will be responsible for close integration \& implementation of,

- Scouting structural hierarchy for the elite category,

- Parameters for Identification, Detection \& Recognition of elite category athletes in line with NSF's KRAs \& KPIs,

- Information sharing of potential elite prospects/athletes with National Scout and the development department.

- He or She will interact with Parents (39), Coaches, Athletes, Trainers \& Support Staff about elite category prospect's,

- General lifestyle,

- Behavior on \& off the field,

- Academic backgrounds,

- Game tactics, match awareness and approach towards the sport, etc.

- He or She will be responsible for detection and evaluation of elite prospects in discussion with Coaches, Support Staff,

Development Team \& NSF Committees based on (39) information shared by the Regional Scouts (Elite) such as,

○ Physical/Physiological fitness parameters,

- Mental or Psychological parameters, and Emotional parameters,

- Behavioral parameters, based on inputs from teammates, parents, coaches, trainers, and NSFs administration.

- Past or recently performances \& growth as a player,

- Team representation \& leadership skills,

- Game tactics, technical parameters, and

- Media \& PR awareness.

- He or She will be the point-of-contact (POC) and face of all elite category scouting-related activities in respective regions.

The hierarchy also has a Scouting Program Manager (Junior Category) part of the process who will be an Indian citizen (Figure 14),

- He or She will play a leading role,

- To ensure implementation of scouting programs/schemes or initiatives for Identification, Detection, and Recognition of potential talents/athletes for junior/sub-junior categories, with Development \& Coaching Departments,

- Segregation of junior/sub-junior category prospects who have potential to represent the sport (38) and the Nation,

- Monitor Scouting Framework (junior/sub-junior category) with National Scout, Coach Advisor \& NDM (Figure 7).

- He or She will be responsible for closely monitoring the progress of,

○ Scouting structural hierarchy for the junior \& sub-junior categories,

- Parameters being used for Identification, Detection, and Recognition of the junior/sub-junior category athletes in line with NSF's KRAs and KPIs,

- Information sharing of potential junior/sub-junior prospects with National Scout and the Development department.

- He or She will interact with parents, Coaches, Athletes, Trainers \& Support Staff (39) about junior \& sub-junior prospect's,

$\circ$ General lifestyle,

- Behavior on \& off the field,

- Academic backgrounds,

- Game tactics, match awareness and approach towards the sport, etc.

- He or She will be responsible for detection and evaluation of junior \& sub-junior prospects in discussion with Coaches, Support Staff, Development Team \& NSF Committees based on (39) information shared by Regional Scouts (Junior) such as,

- Physical/Physiological fitness parameters,

- Mental or Psychological parameters, and Emotional parameters,

- Behavioral parameters, based on inputs from teammates, parents, coaches, trainers, and NSFs administration.

- Past or recently performances \& growth as a player,

- Team representation \& leadership skills,

- Game tactics, technical parameters, and Media \& PR awareness

- He or She will be the point-of-contact and face of all junior \& sub-junior category scouting activities in respective regions.

The hierarchy also has Talent Verification Program Head part of the process who will be an Indian citizen (Figure 14), 
- He or She will play a leading role,

- To ensure implementation of "talent/athlete verification policies" for cross-checking the Identification, Detection, and Recognition of potential prospects as per data \& information shared by Development \& Coaching Departments,

- For segmentation of potential prospects, from tournaments based on information shared by the Scouting \& Coaching Departments (38) either for growth via exposure or for further development via programs \& initiatives.

- Monitor Talent/Athlete verification policy implementation \& structural delegation at all levels of the hierarchy.

- He or She will be responsible for closely monitoring the integration progress of,

- Talent Verification structural hierarchy,

- Parameters for verification \& judgment of prospects/athletes in line with the NSF's KRAs and KPIs,

○ Information sharing of potential talents/athletes with the Coaching, Scouting, and Development Departments.

- He or She will verify \& validate interactions with Parents, Coaches, Athletes, Trainers about the prospects/athletes and,

$\circ$ Further maintain the information, comments, or additional data shared by Regional Talent Verification Managers.

- He or She will be responsible for final verification and validation of talents/athlete's data in discussion with Development Department \& NSF Committees (39), as per reports shared by Regional Verification Managers and the first level data by shared Scouting \& Coaching Departments.

- He or She will be responsible for keeping the NSFs up-to-date with the Athlete Verification norms \& strategic developments for further innovation, policy development \& amendments to the existing process or procedures.

- He or She will be the point-of-contact (POC) for all athlete verification \& validation-related strategic activities in the country.

Furthermore, we have Regional Scouts (Elite Category) part of the process who will be an Indian citizen (Figure 15),

- He or She will play a leading role for,

$\circ$ Ensuring on-ground application of scouting programs/schemes or initiatives for Identification, Detection, and Recognition of potential elite talents/athletes, in association with Development \& Coaching Departments,

- Segregation of elite prospects/talents/athletes who have the potential to represent the sport (38) and the Nation,

$\circ \quad$ On-ground implementation of Scouting Framework (Elite) with National Scout, Coach Advisor \& NDM (Figure 7).

- He or She will be responsible for effective, efficient, resourceful and successful execution of,

- Talent/Athlete scouting strategically aligned processes for the elite category,

- Parameters for Identification, Detection \& Recognition of elite category athletes in line with NSF's KRAs \& KPIs,

- Information sharing of potential elite prospects/athletes with National Scout and the Development department.

- He or She will interact with Parents (39), Coaches, Athletes, Trainers \& Support Staff about elite category prospect's,

$\circ$ General lifestyle,

- Behavior on \& off the field,

$\circ$ Academic backgrounds,

- Game tactics, match awareness and approach towards the sport, etc.

- He or She will have to travel significantly to scout, collect data \& meet the elite prospects/athletes in person.

- He or She will be responsible for maintaining working/professional relationships with local sports authorities, clubs, academies, schools, healthcare, childcare centers, etc. to gain relevant \& valid information for the framework to work.

- He or She will be responsible for on-ground \& in-person evaluation of elite prospects on parameters such as,

- Physical/Physiological fitness parameters,

- Mental or Psychological parameters,

- Emotional parameters,

- Behavioral parameters, based on inputs from teammates, parents, coaches, trainers, and NSFs administration.

- Past or recently performances \& growth as a player,

○ Team representation \& leadership skills,

$\circ$ Game tactics, technical parameters, and

- Media \& PR awareness,

- He or She will be responsible for sending NSF-specific reports on identified \& detected prospects considering all the above parameters, with all necessary documents, data \& information deemed relevant for the NSF departments for better judgment.

- He or She will be the point-of-contact (POC) and face of all elite category scouting activities in the respective region(s).

We also have Regional Scouts (Junior/Sub-Junior Category) part of the process who will be an Indian citizen (Figure 15),

- He or She will play a leading role for, 
- Ensuring on-ground application of scouting programs/schemes or initiatives for Identification, Detection, and Recognition of potential e talents/athletes, in association with Development \& Coaching Departments,

- Segregation of junior/sub-junior talents/athletes who have potential to represent the sport ${ }^{(38)}$ and the Nation,

- On-ground implementation of Scouting Framework (Elite) with National Scout, Coach Advisor \& NDM (Figure 7).

- He or She will be responsible for effective, efficient, resourceful and successful execution of,

- Talent/Athlete scouting strategically aligned processes for the junior/sub-junior category,

- Parameters for Identification, Detection, and Recognition of junior/sub-junior athletes in-line with KRAs \& KPIs,

- Information sharing of potential elite prospects/athletes with National Scout and the Development department.

- He or She will interact with Parents (39), Coaches, Athletes, Trainers \& Support Staff about junior/sub-junior prospect's,

$\circ$ General lifestyle,

- Behavior on \& off the field,

- Academic backgrounds,

- Game tactics, match awareness and approach towards the sport, etc.

- He or She will have to significantly travel to scout, collect data \& meet the junior/sub-junior prospects/athletes in person.

- He or She will be responsible for maintaining working/professional relationships with local sports authorities, clubs, academies, schools, healthcare \& childcare centers to gain relevant information for the framework to work.

- He or She will be responsible for on-ground \& in-person evaluation of junior/sub-junior prospects on parameters such as,

- Physical/Physiological fitness parameters,

- Mental or Psychological parameters and Emotional parameters,

- Behavioral parameters, based on inputs from teammates, parents, coaches, trainers, and NSFs administration.

- Past or recently performances \& growth as a player,

- Team representation \& leadership skills,

- Game tactics, technical parameters, and

- Media \& PR awareness,

- He or She will be responsible for sending NSF-specific reports on identified \& detected prospects considering all the above parameters, with all necessary documents, data \& information deemed relevant for the NSF departments for better judgment.

- He or She will be the point-of-contact (POC) and face of all junior/sub-junior category scouting activities in the region(s).

Last but not the least, we have Regional Talent Verification Manager part of the process who will be an Indian citizen (Figure 15),

- He or She will play a leading role for,

- Ensuring implementation of "talent/athlete verification policies" for cross-checking the Identification, Detection, and the Recognition of potential prospects as per information shared by Development \& Coaching Departments,

- Segmentation of potential prospects from tournaments based on the information given out by Scouting \& Coaching Departments (38) either for growth via exposure or for further development via schemes/programs \& initiatives,

- Monitoring talent/athlete verification policy implementation \& structural delegation at all levels of the hierarchy,

- He or She will be responsible for closely monitoring the integration progress of,

○ Talent Verification structural hierarchy,

- Parameters for verification \& judgment of prospects/athletes in line with the NSF's KRAs and KPIs,

- Information sharing of potential talents/athletes with the Coaching, Scouting, and Development Departments.

- He or She will verify \& validate interactions with Parents, Coaches, Athletes, Trainers about the prospects/athletes and,

- Further maintain the information, comments, or additional data shared by Regional Talent Verification Managers.

- He or She will be responsible for final verification and validation of talents/athlete's data in discussion with Development Department \& NSF Committees ${ }^{(39)}$, as per reports shared by Regional Verification Managers and the first level of data by Scouting \& Coaching Departments.

- He or She will be responsible for keeping the NSFs up-to-date with the Athlete Verification norms \& strategic developments for further innovation, policy development $\&$ amendments to the existing process or procedures.

- He or She will be the point-of-contact (POC) for all athlete verification \& validation-related strategic activities in the regions.

The framework will have to be carefully re-worked, and strategically aligned for further development and substantial growth of Paralympic Sports ${ }^{(40)}$ in India, as the usual identification methods won't be applicable. Therefore, detection and recognition methods of para-athletes or athletes who are differently/specially abled have to be carried out, based on classification code or rules ${ }^{(41)}$ put in place by the global governing body for Paralympic sport. 


\section{FINANCIAL FIgURES \& FRAMEWORK HiERARCHY ILLUSTRATIONS.}

Sports Authority of India (SAI) ACTC 2019 - Financials for respective NSFs*

in Millions (Mn)

600

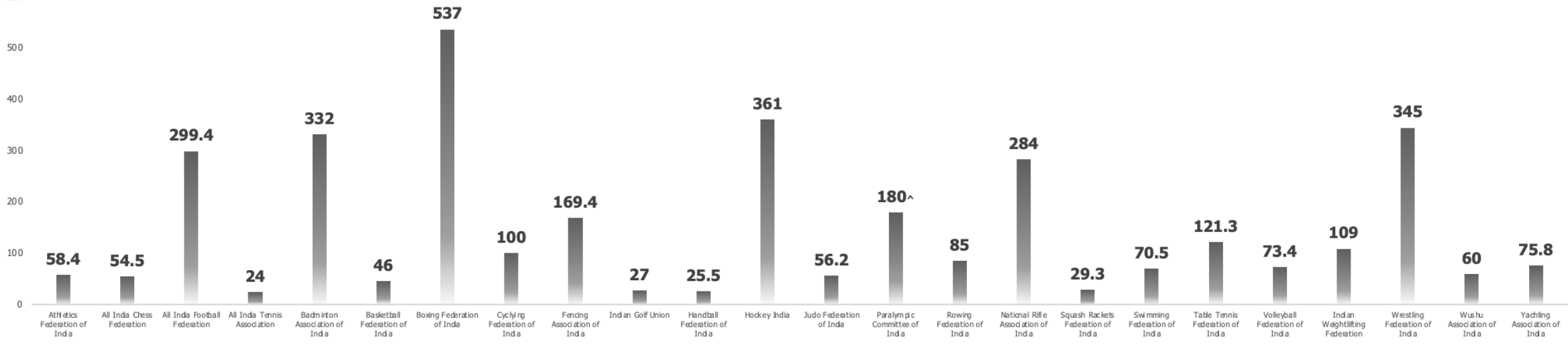

NPSF- National Sports Federations
NParlympic Committee of India budget includes budget for Special Olympic Bharat (60 Mn) \& All India Sports Council of the Deaf (20 Mn.)

"All amounts are in Millions | Curreny consideration INR

Data Source: https:///actc.sports
Prepared by: Hitesh Mangtani

Figure 1. Coaching and Scouting: A managerial framework for Sports Development in the Indian sub-continent. | Sports Authority of India (SAI) ACTC 2019 - Financials for NSFs in Millions (Mn).

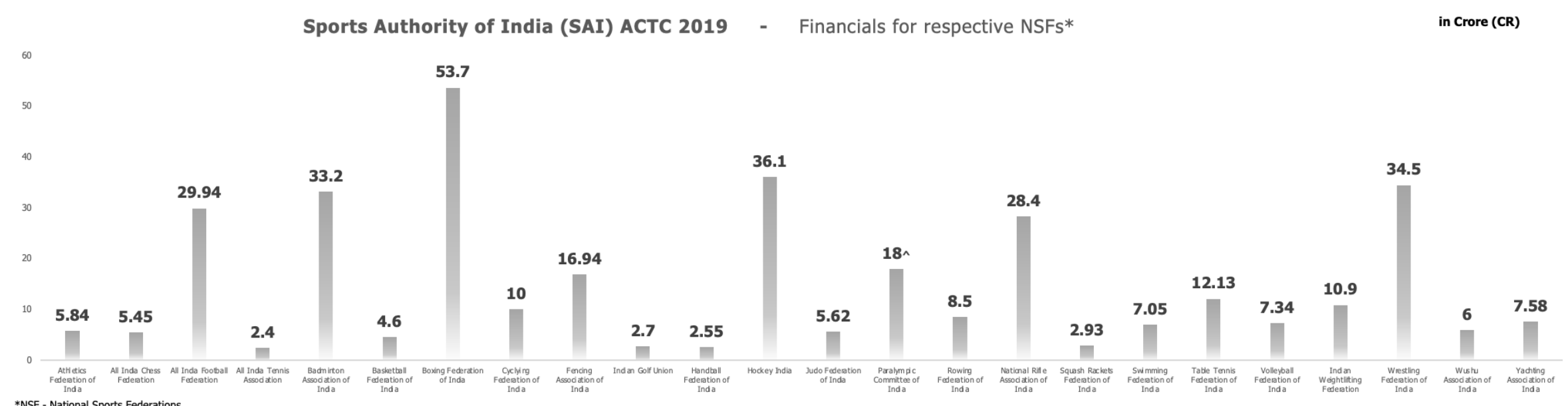

Figure 2. Coaching and Scouting: A managerial framework for Sports Development in the Indian sub-continent. | Sports Authority of India (SAI) ACTC 2019 - Financials for NSFs in Crore (CR).

This publication is licensed under Creative Commons Attribution CC BY. 


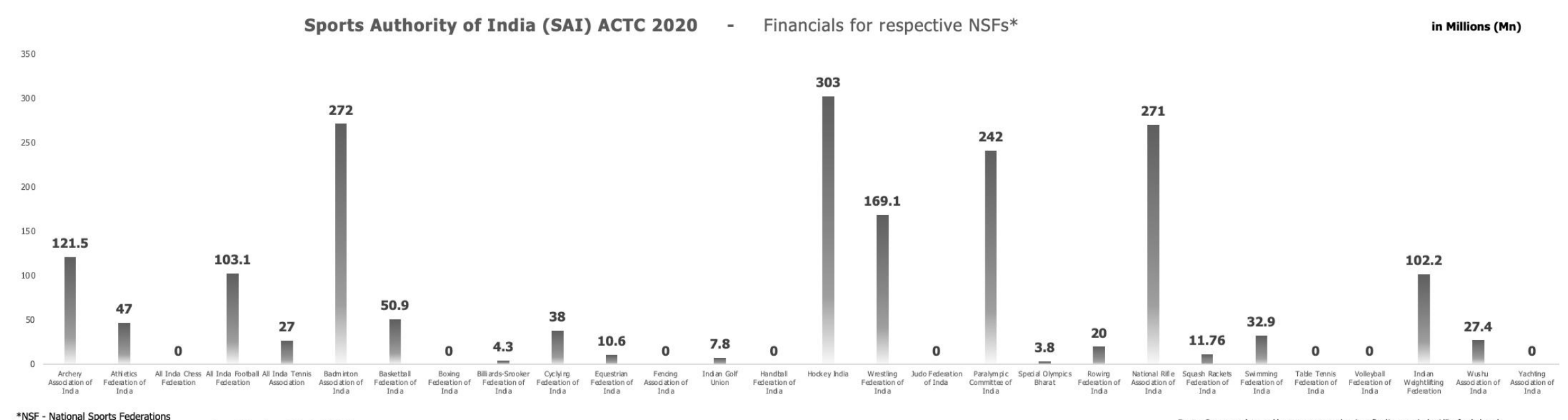

\section{*NSF - National Sports Federations
'O': Financials are not presented or approved as of Monday - 19 th April 2021}

Data Source: htpp:///actc.sport
Prepared by: Hitesh Mangtani

Figure 3. Coaching and Scouting: A managerial framework for Sports Development in the Indian sub-continent. | Sports Authority of India (SAI) ACTC 2020 - Financials for NSFs in Millions (Mn).

Sports Authority of India (SAI) ACTC 2020 - Financials for respective NSF**

in Crore (CR)

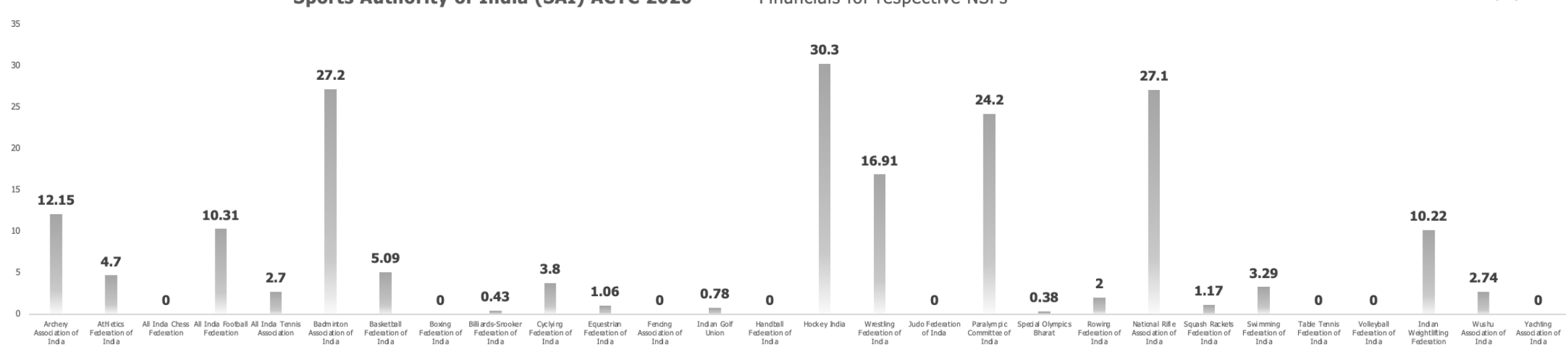

\section{*NSF - National Sports Federations}

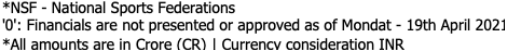

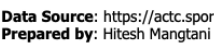

Figure 4. Coaching and Scouting: A managerial framework for Sports Development in the Indian sub-continent. | Sports Authority of India (SAI) ACTC 2020 - Financials for NSFs in Crore (CR).

This publication is licensed under Creative Commons Attribution CC BY. 
This publication is licensed under Creative Commons Attribution CC BY. 


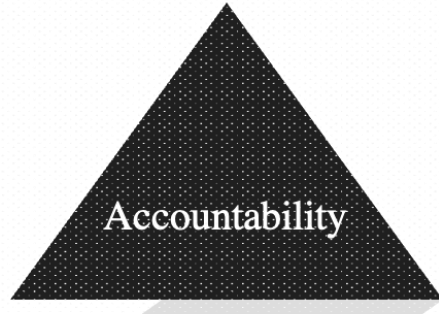

Extensive fundamental understanding and awareness of/about Indian Sports Ecosystem

Top-Down Approach

Marco Level understanding and

awareness about Sports Industry of

respective global ecosystems

Strategic alignment of sports

specific products \& services

while being competitive for

market penetration

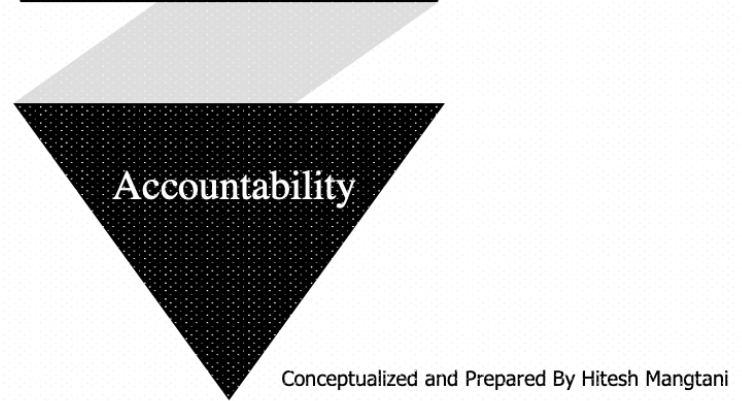

Figure 5. Coaching and Scouting: A managerial framework for Sports Development in the Indian sub-continent.| Bottoms-Up Approach \& Top-Down Managerial Approach.

Region \& Community specific information or data for Sports specific market(s) segmentation at the Micro Level.

\section{Bottom-Up Approach}
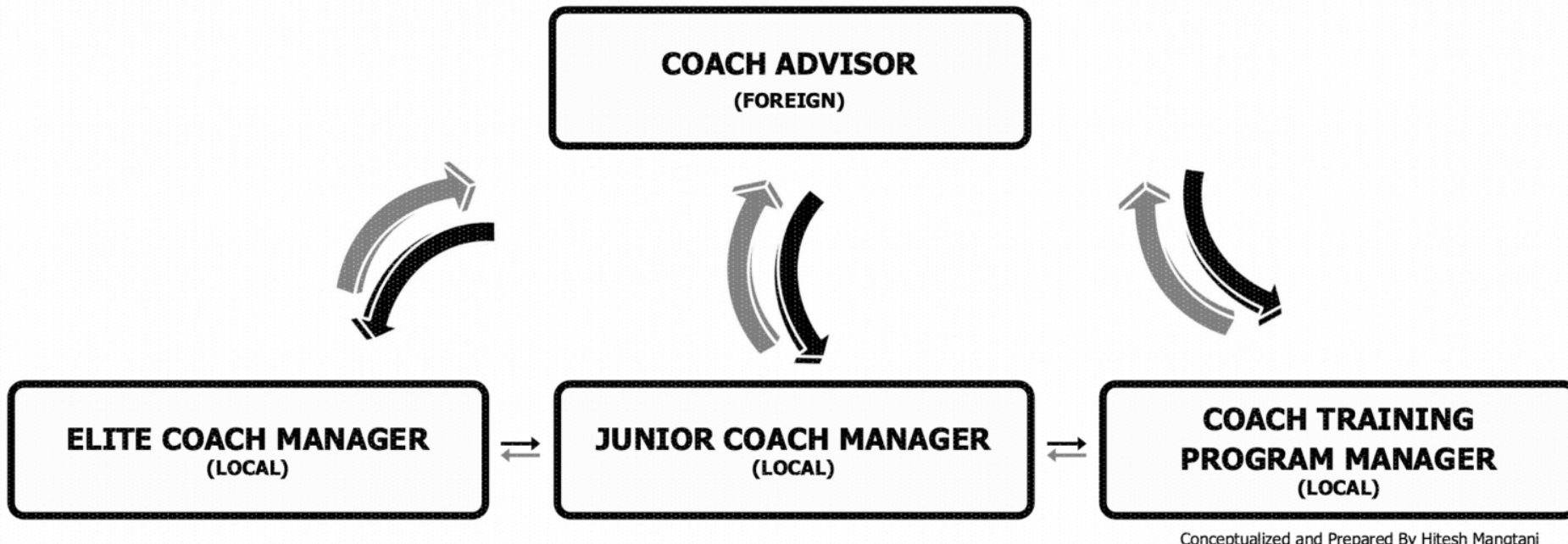

Figure 6. Hierarchy for Coaching and Scouting: A managerial framework for Sports Development in the Indian sub-continent.| Level - 1. 


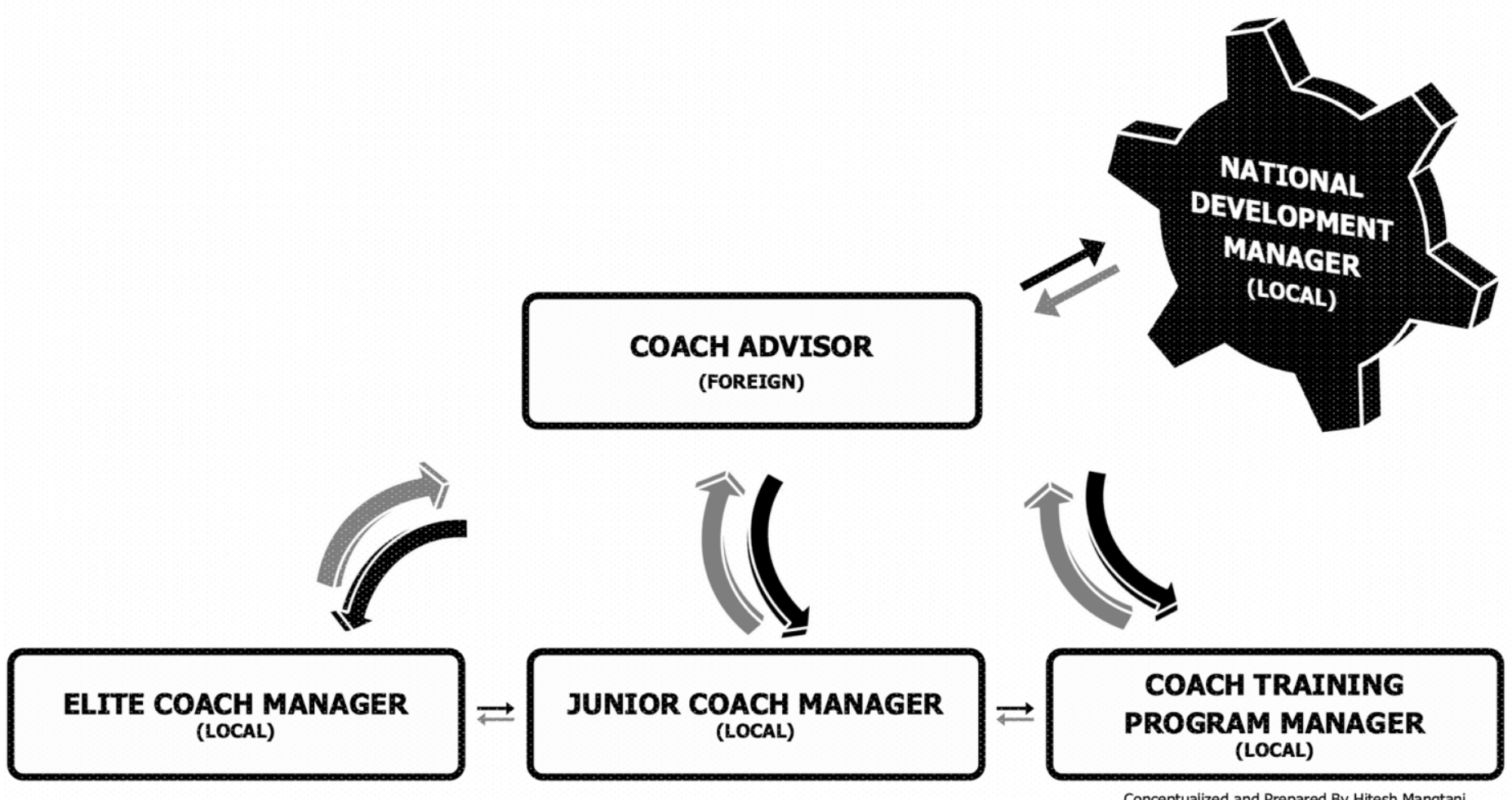

Figure 7. Hierarchy for Coaching and Scouting: A managerial framework for Sports Development in the Indian sub-continent.| Level-1.1.
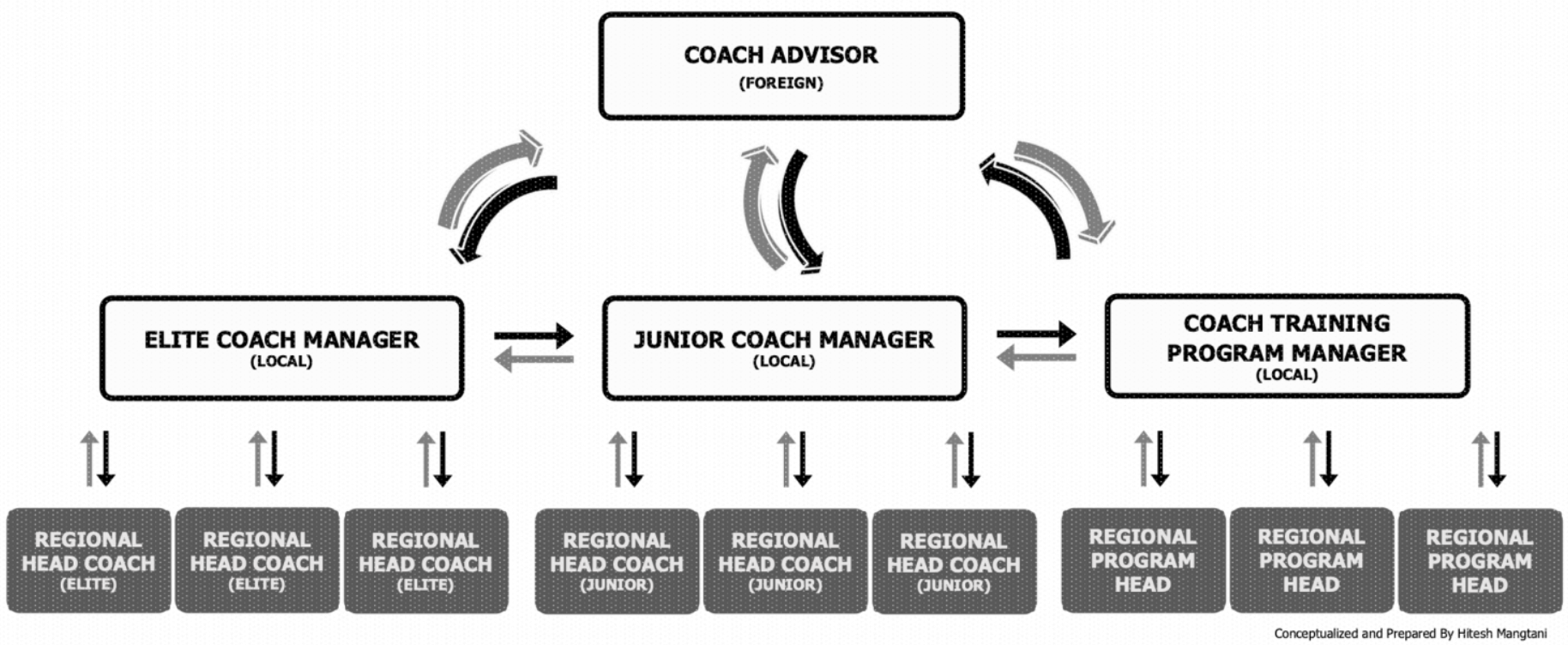

Figure 8. Hierarchy for Coaching and Scouting: A managerial framework for Sports Development in the Indian sub-continent. | Level - 2. 


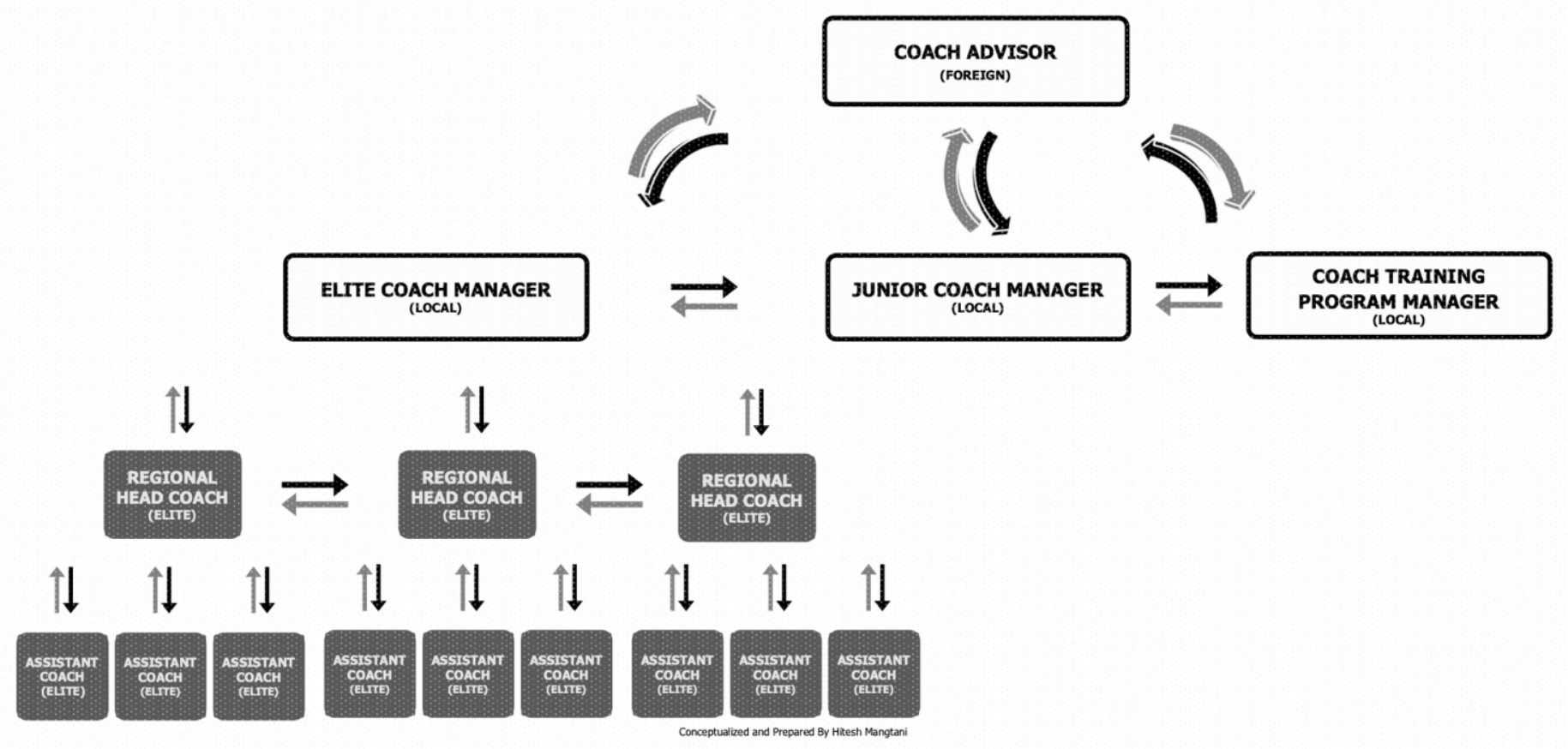

Figure 9. Hierarchy for Coaching and Scouting: A managerial framework for Sports Development in the Indian sub-continent.| Level-3.1.

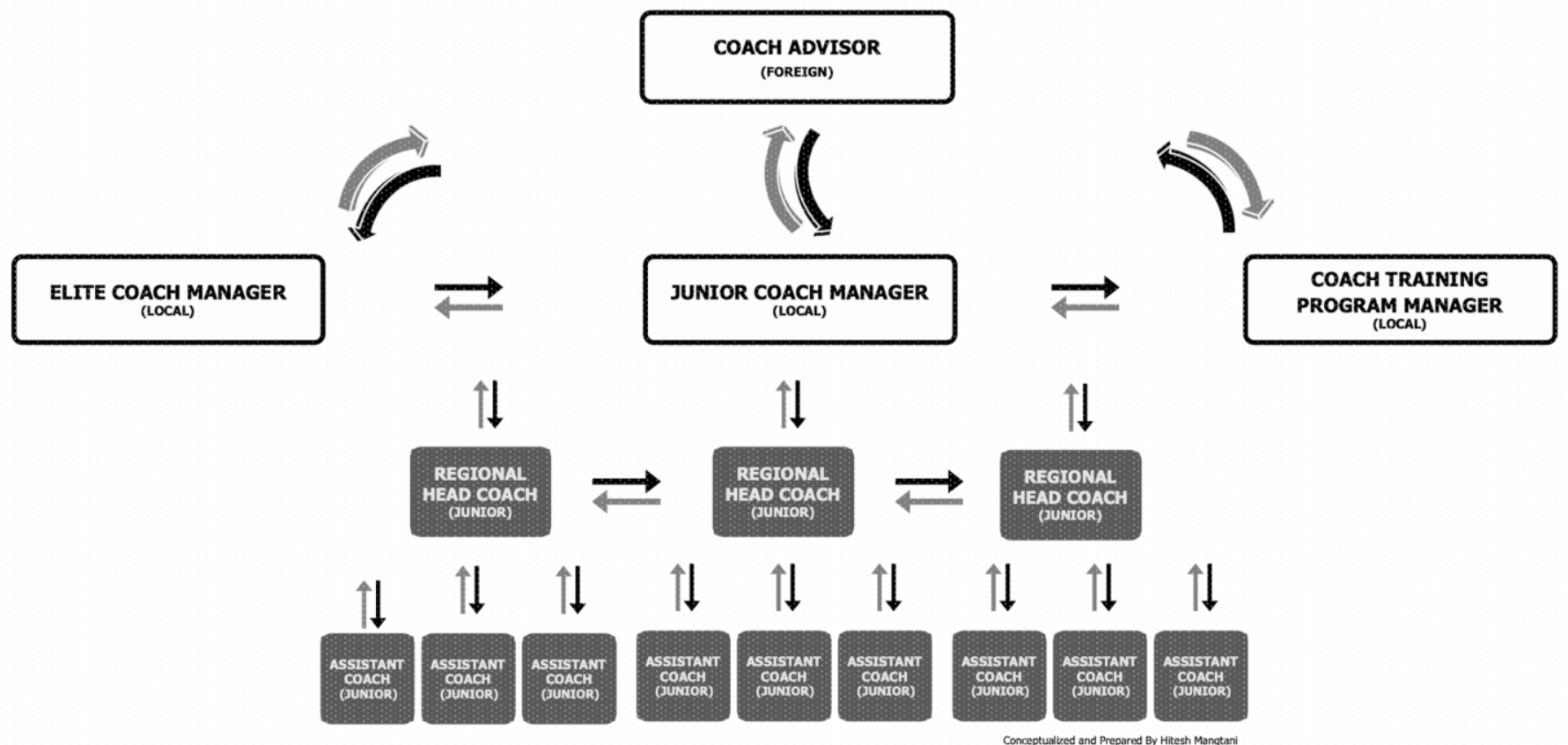

Figure 10. Hierarchy for Coaching and Scouting: A managerial framework for Sports Development in the Indian sub-continent.| Level-3.2. 


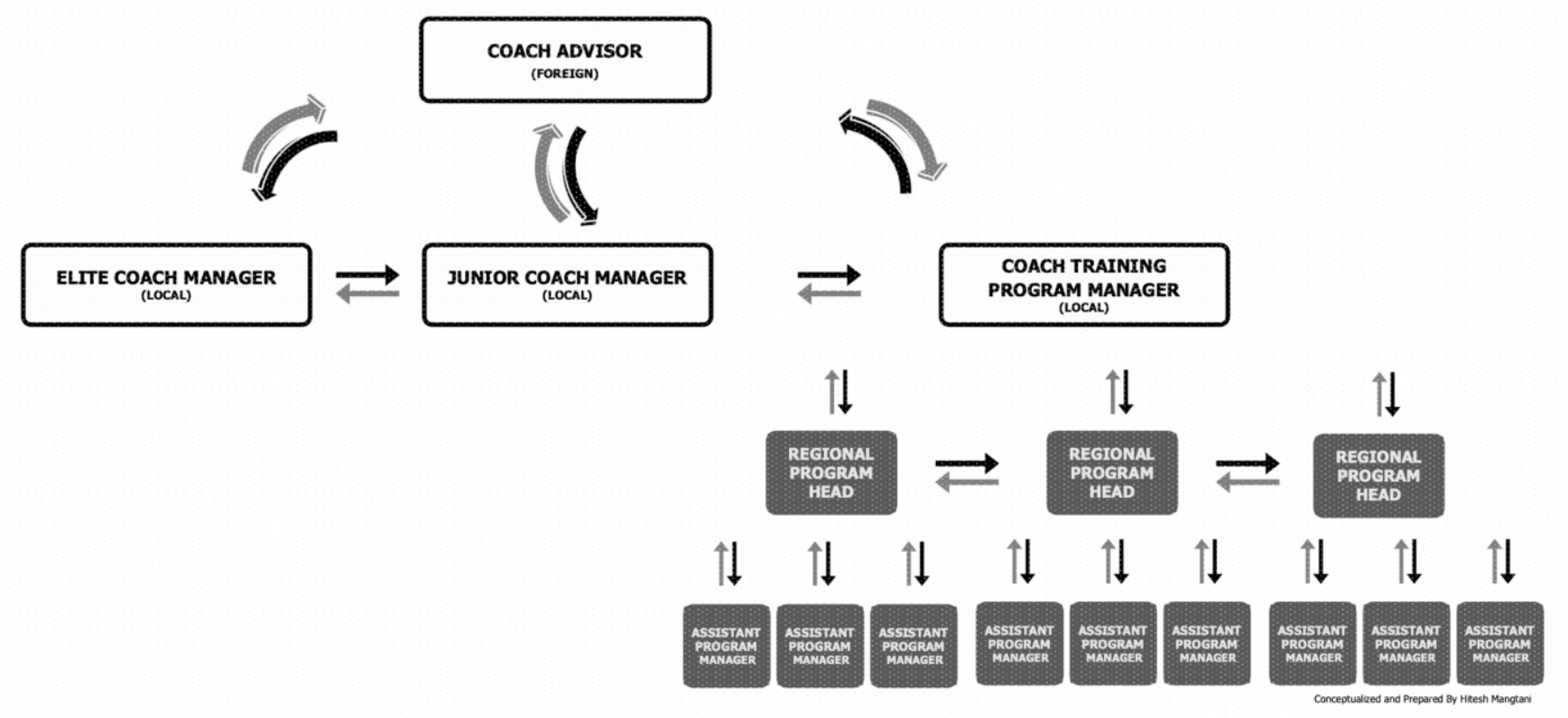

Figure 11. Hierarchy for Coaching and Scouting: A managerial framework for Sports Development in the Indian sub-continent.| Level-3.3.

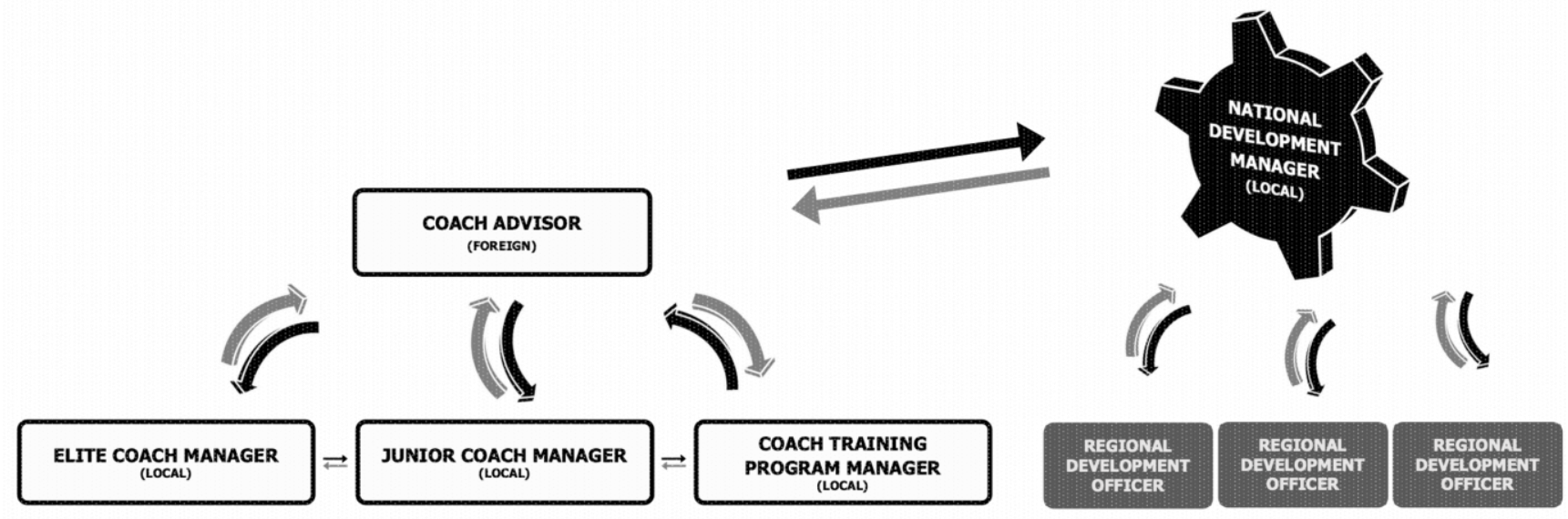

Figure 12. Hierarchy for Coaching and Scouting: A managerial framework for Sports Development in the Indian sub-continent.| Development Hierarchy Level-2.1.

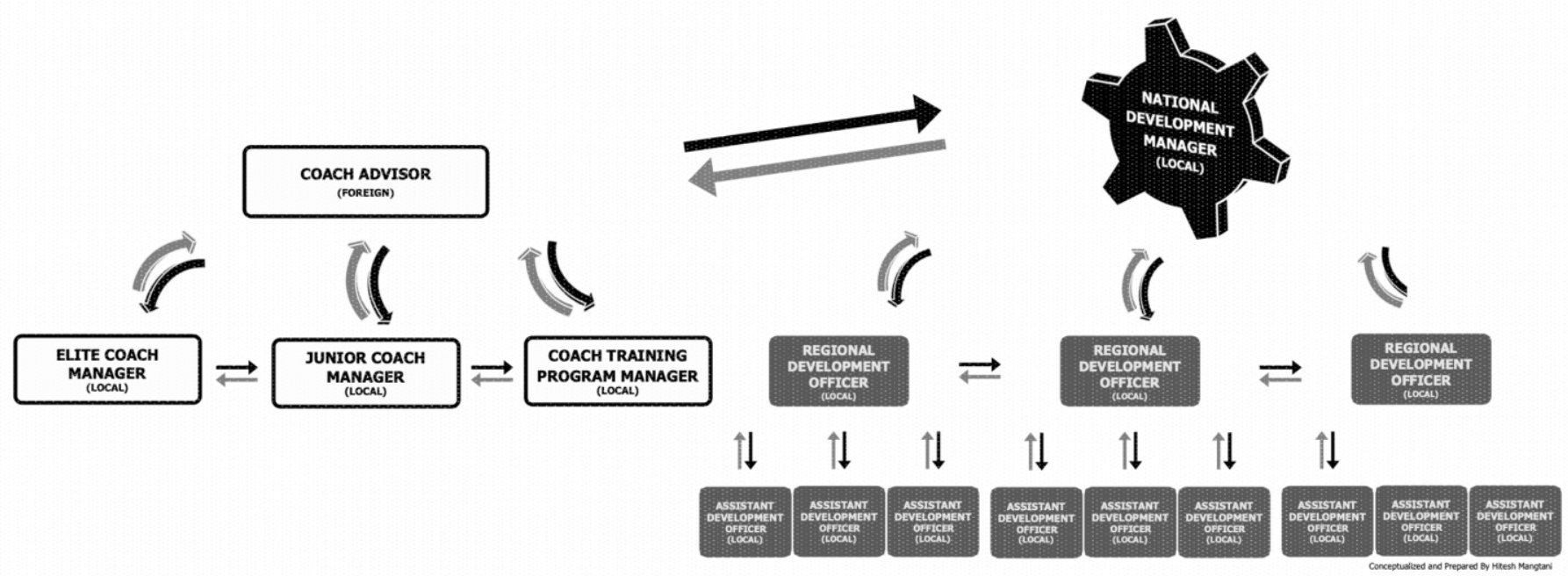

Figure 13. Hierarchy for Coaching and Scouting: A managerial framework for Sports Development in the Indian sub-continent.| Development Hierarchy Level-2.2. 


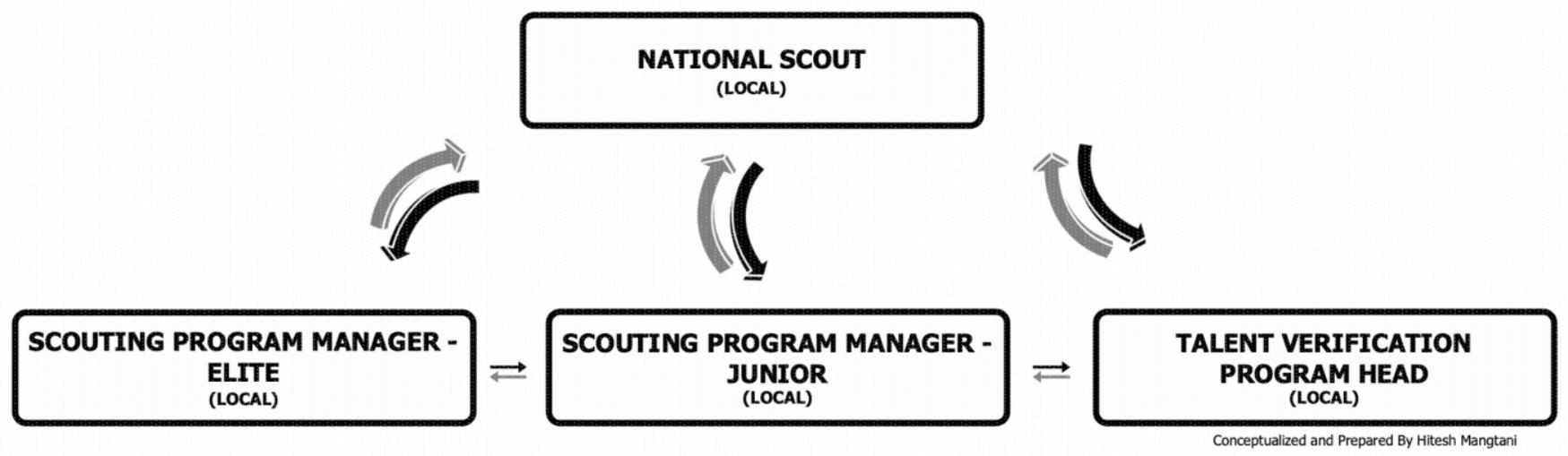

Figure 14. Coaching and Scouting: A managerial framework for Sports Development in the Indian sub-continent. | Scouting Structural Hierarchy 1.1

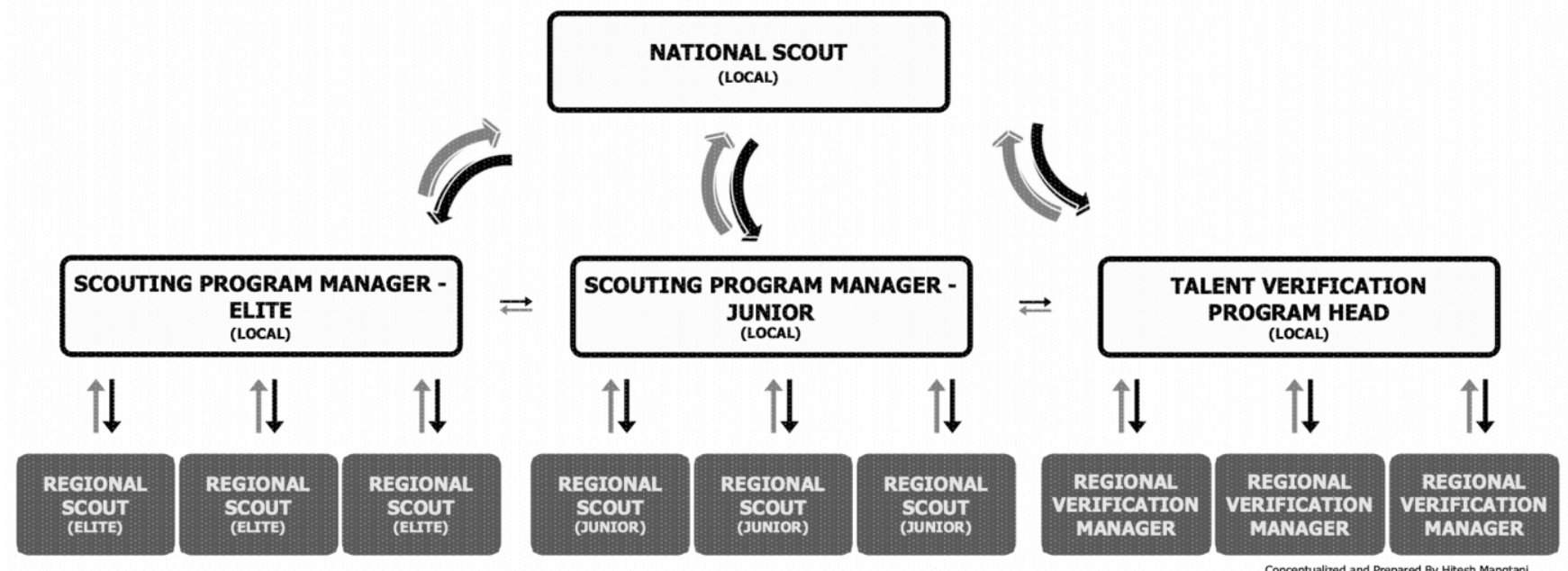

Figure 15. Coaching and Scouting: A managerial framework for Sports Development in the Indian sub-continent.| Scouting Structural Hierarchy 1.2
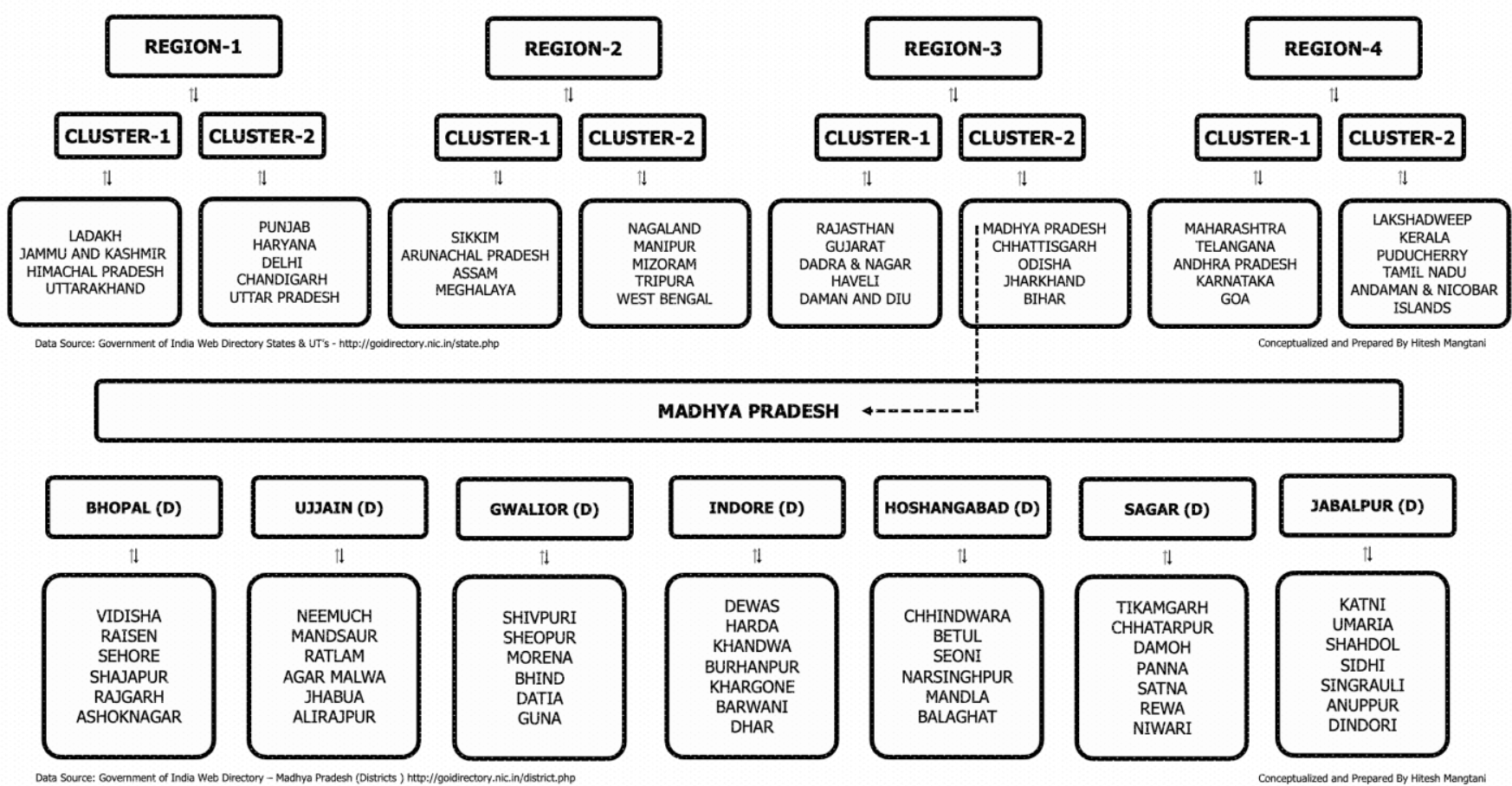

Figure 16. Coaching and Scouting: A managerial framework for Sports Development in the Indian sub-continent. | Implementation Hierarchy - Regions, Clusters Divisions. 


\section{Conclusion}

Globally, the human race has a substantial presence with a world population of $7.67 \mathrm{Bn}$ people ${ }^{(42)}$. India alone accounts for nearly $17 \%$ to $18 \%$ of the Global Population as of 2019 , i.e., $1.36 \mathrm{Bn}$ or $136 \mathrm{Cr}$ people ${ }^{(43)}$. Furthermore, out of the total population in India, nearly $52 \%$ are Male, i.e., close to $702 \mathrm{Mn}$ or $70.2 \mathrm{Cr}$, and close to $48 \%$ are Female, i.e., close to $652.8 \mathrm{Mn}$ or $65.28 \mathrm{Cr}$ if compared to 3.86 Bn Males which accounts for 50.3\% and 3.80 Bn Females which account for 49.5\% of the Total Global Population (42) respectively. Every Nation and respective International Organizations concerned about such huge numbers are committed to providing a safe and healthy ${ }^{(44)(45)}$ environment to each individual residing in any of the communities or willing to relocate anywhere in the world, within the legal boundaries of the system. United Nations - Department of Economic and Social Affairs recently launched an advocacy brief ${ }^{(46)}$ with an eye-opening approach for reviving, reclamation, and renovation of Global Economies and the Economics of sports in a collective way. We will have to immensely focus on the development and enhancement of sporting disciplines via directing our attention towards Talent/Athlete Identification, Recognition \& Development ${ }^{(47)}$ using a variety of methods, models (48), and the framework's similar to what we have visualized through this extensive \& exclusive discussion, particularly for the Indian Sports Ecosystem. For any of these methods, models ${ }^{(48)}$, or frameworks to work, we must be giving equal importance to the growth of athletes and the growth of scouts, coaches, and a scouting and coaching framework that has to be built, maintained \& enhanced. While being in line with the IOC's, IPC's, ISF's, National Governing Body's and NSF's vision, mission goals, objectives, key research areas (KRAs), key performance indicators (KPIs), and values, so that the Sports Ecosystem in that respective region (India in this case) can flourish, not just from being a breeding ground of champions but also from a sports management or traditional management point of view to build a self-sustainable sports ecosystem in the country.

This Coaching and Scouting framework for Sports Development, with specific suggestions and ideas for the management of the sports ecosystem in India in terms of managing the growth and reputation of coaches, scouts, support staff, and administrators - who work behind the scene and round the clock with the potential champions and prospects in-order to groom them in the right way to the best of their capabilities, can be (in fact has to be) our way forward if Sports Governing Bodies, NSFs in India wish to make a mark at the world stage, and further want to be considered as one of the best in the world in terms of Sports Management and Governance. Management of a framework similar to Coaching and Scouting managerial framework for Sports Development, especially in the Indian sub-continent, is like succession planning for the system to work seamlessly with every department such as Coaching, Scouting, Development, Marketing, Public Relations, etc., are aware of their roles and responsibilities for the ecosystem to be fully functional \& independent. If not, the whole industry (in this case Indian Sports Ecosystem) will have to bear the cost (49) of poor planning and supervision efforts. With more and more athletes qualifying for the Olympics \& Paralympics Games around the world, management frameworks like this would reveal more opportunities for such participants to share their stories and tactics for the upcoming athletes to learn from it, apply their own positives (including the negatives) and move forward with a new set of processes for each of them to succeed and ensure we get new set of learning tools and experiences, exactly like a circle of improvement.

\section{REFERENCES}

[1] Lloyd, Rhodri S.1; Oliver, Jon L.1; Faigenbaum, Avery D.2; Howard, Rick3; De Ste Croix, Mark B. A.4; Williams, Craig A.5; Best, Thomas M.6; Alvar, Brent A.7; Micheli, Lyle J.8,9,10; Thomas, D. Phillip11; Hatfield, Disa L.12; Cronin, John B.13,14; Myer, Gregory D.10,15,16,17 Long-Term Athletic DevelopmentPart 1, The Journal of Strength \& Conditioning Research: May 2015 - Volume 29 - Issue 5 - p 1439-1450 doi: 10.1519/JSC.0000000000000756

[2] United Nations Statistical Division (UNSD), (2020). The Sustainable Development Goals Report 2020. Available at: https://unstats.un.org/sdgs/report/2020/TheSustainable-Development-Goals-Report-2020.pdf.

[3] Jain, Sankalp, Sports Administration in India: Legislative Framework and Judicial Pronouncements (June 14, 2020). Available at SSRN: https://ssrn.com/abstract=3626923 or http://dx.doi.org/10.2139/ssrn.3626923

[4] McLeod, J., Shilbury, D., \& Zeimers, G. (2020). An Institutional Framework for Governance Convergence in Sport: The Case of India, Journal of Sport Management, , 1-14. Available at: https://journals.humankinetics.com/view/journals/jsm/aop/article-10.1123-jsm.2020-0035/article-10.1123-jsm.2020-0035.xml

[5] Kerr-Lazenby, M., 2020. Eden Park Fans 'Super Stoked' To Snap Up Auckland Stadium's Hallowed Turf. Available at: <https://www.stuff.co.nz/sport/rugby/300190644/eden-park-fans-super-stoked-to-snap-up-auckland-stadiums-hallowed-turf>.

[6] Cricket.com.au, 2021. How Aussies Plan For Their Opposition With Dene Hills. Available at: 〈https://www.youtube.com/watch?v=9CIUAsDNL0o>.

[7] Cricket.com.au, 2020. Behind The Bubble: Managing Injuries In A COVID World. Available at: 〈https://www.youtube.com/watch?v=dZTJTbhlu6o>.

[8] SAI, (2019). ACTC Calendar And Budget, from https://actc.sportsauthorityofindia.gov.in/sai/Default.html

[9] SAI, (2020). ACTC Calendar And Budget, from https://actc.sportsauthorityofindia.gov.in/sai/Default.html

[10] Higgs, C., Way, R., Harber, V., Jurbala, P. and Balyi, I., 2021. Long-Term Development In Sport And Physical Activity 3.0 | Sports For Life. Third Edition. Available at: <https://sportforlife.ca/resources/>.

[11] Balyi, I. (2004). Long-Term Athlete Development: Trainability in Childhood and Adolescence - Windows of Opportunity, Optimal Trainability.

[12] Olympic.org, (2021). Paris 2024 Summer Olympics - Summer Olympic Games in France, from https://www.olympic.org/paris-2024

[13] Paralympic.org, (2021). Paris 2024 - 2024 Paralympic Games | International Paralympic Committee, from https://www.paralympic.org/paris-2024

[14] Olympic.org, (2021). LA 2028 Summer Olympics - Summer Olympic Games in the USA, from https://www.olympic.org/la-2028

[15] Paralympic.org, (2021). LA28 kicks off journey to 2028 by unveiling new emblem, from https://www.paralympic.org/news/la28-kicks-journey-2028-unveilingnew-emblem 
[16] ANI News, (2021). Sports Science expert Sokolovas to interact with Swimmers; TOPS to cover expenses, from https://www.aninews.in/news/sports/others/sportsscience-expert-sokolovas-to-interact-with-swimmers-in-national-camp-tops-to-cover-expenses20210113130322/

[17] Paralympic Committee of India (PCI), (2021). PCI partners with SIDBI to support Para Athletes' Tokyo 2020 training, from https://paralympicindia.org.in/web/post/pci-sidbi.

[18] Lopez Frias, Francisco Javier \& Isidori, Emanuele. (2014). Sport and Democracy: Philosophical Trends and Educational Challenges in Contemporary Society. Cultura, Ciencia y Deporte. 9. 189-197. 10.12800/ccd.v9i27.461.

[19] Balasubramanian, S. and Santhanam, V., (2014). Book: The Business Of Cricket - The Story Of Sports Marketing In India. First Edition . Harper Collins.

[20] Medium, 2016. Top-Down Vs. Bottom-Up Approaches: Which Is Right For You? Available at: <https://medium.com/@Clarizen/top-down-vs-bottom-upapproaches-which-is-right-for-you-d157715ecd95>.

[21] Walker, B. \& Soule, S., 2017. Changing Company Culture Requires A Movement, Not A Mandate. Harvard Business Review.<https://hbr.org/2017/06/changingcompany-culture-requires-a-movement-not-a-mandate>.

[22] Zenger, J., \& Folkman, J. (2020). What Makes a 360-Degree Review Successful? Retrieved 20 January 2021, from https://hbr.org/2020/12/what-makes-a-360degree-review-successful?utm_campaign=hbr\&utm_medium=social\&utm_source=linkedin

[23] Mangtani, H. (2019). Designated Centers for Sport Rejuvenation and Stadia Performance Evaluation. Retrieved from https://www.linkedin.com/pulse/designatedcenters-sport-rejuvenation-stadia-hitesh-harry-mangtani?trk=portfolio_article-card_title

[24] National Informatics Centre (NIC), (2021). States \& UTs | Government of India Web Directory. Available on: http://goidirectory.nic.in/state.php

[25] National Informatics Centre (NIC), (2021). Districts | Government of India Web Directory. Available on: http://goidirectory.nic.in/district.php

[26] NSDF, 2021. National Sports Development Fund (NSDF) | Ministry Of Youth Affairs And Sports (MYAS) | Government of India (GOI). Available at: $<$ https://yas.nic.in/sports/national-sports-development-fund-0>.

[27] Press Trust of India (PTI) \& SPORTSTAR, (2021). Manu Bhaker, Angad Bajwa's proposal to engage sports psychologist approved. Available at: https://sportstar.thehindu.com/shooting/manu-bhaker-angad-bajwas-proposal-to-engage-sports-psychologistapproved/article33617544.ece?utm_source=latestnews\&utm_medium=web\&utm_campaign=read

[28] Mangtani, H. and Laskar, T., (2020). Sponsorship: A Million Ways To Tell Your Brand Story by ITW Core, ITW Consulting Pvt. Ltd. Available at: <https://itwconsulting.in/sponsorship-a-million-ways-to-tell-your-brand-story/>.

[29] Mangtani, H., \& Laskar, T. (2020). Brand Ambassadors are passé: It's an influencer's world now by ITW Core, ITW Consulting Pvt. Ltd. Available at: https:/itwconsulting.in/brand-ambassadors-are-passe-its-an-influencers-world-now/

[30] Medium, (2019). Sports Industry Insights. Available on: https://medium.com/qara/sports-industry-report-3244bd253b8

[31] Dsouza, N. (2019). Sports sponsorship has grown by 12\%: Vinit Karnik, ESP Properties, GroupM - Exchange4media., Available on: https://www.exchange4media.com/ipl-news/sports-sponsorship-has-grown-by-12-vinit-karnik-esp-properties-groupm-95865.html

[32] Antoine Noël Racine, Aurélie Van Hoye, Anne Boyd, Flora Jackson, Jean-Marie Garbarino, Bernard Massiera, Sonja Kahlmeier, Petru Sandu \& Anne Vuillemin (2020) A scoping review of published research on local government policies promoting health-enhancing physical activity, International Journal of Sport Policy and Politics, 12:4, 747-763, DOI: 10.1080/19406940.2020.1816561

[33] WHO (2020). WHO's COVID-19 Response Available at: 〈https://www.who.int/emergencies/diseases/novel-coronavirus-2019/interactive-timeline\#event-0>.

[34] Klassen, T., 2020. The Politics Of COVID-19 Results In Pandemic Winners And Losers. Available at: https://theconversation.com/the-politics-of-covid-19results-in-pandemic-winners-and-losers-150604.

[35] MacInnes, P. (2021). How data is pushing Twitter scouts and bloggers into football's big time. Available at: https://www.theguardian.com/football/2021/feb/27/how-data-is-pushing-twitter-scouts-and-bloggers-into-footballs-big-time

[36] Fernandes (OLY), S., \& Mangtani, H. (2021). Sports Development: A template for amplifying athlete(s) or team(s) performance. Available at: https://www.linkedin.com/pulse/sports-development-template-amplifying-athletes-teams-mangtani?trk=public_profile_article_view

[37] The Print, 2021. Decoding new MMDR Act as Modi govt pushes long-awaited mining reforms in India. Available at: https://www.youtube.com/watch?v=ZDejfiY3z5k.

[38] Chicago Cubs, 2018. The Story Behind the Chicago Cubs Scouting Process. Available at: https://www.youtube.com/watch?app=desktop\&v=_I1T1bfkE6w

[39] Arizona Diamondbacks, 2019. A Day in the Life of an Arizona Diamondbacks Scout. Available at: https://www.youtube.com/watch?v=ZkIGgN15Qww

[40] Dehghansai N, Pinder RA and Baker J (2021) "Looking for a Golden Needle in the Haystack": Perspectives on Talent Identification and Development in Paralympic Sport. Front. Sports Act. Living 3:635977. doi: 10.3389/fspor.2021.635977

[41] International Paralympic Committee (IPC) Classification Code. Available at: https://www.paralympic.org/classification-code.

[42] The World Bank (2019). Total Population Data. Available at: https://data.worldbank.org/indicator/SP.POP.TOTL?end=2019\&start=1960

[43] The World Bank (2019). Total Population - India Data. Available at: https://data.worldbank.org/indicator/SP.POP.TOTL?locations=IN

[44] Callaghan, S., Lösch, M., Pione, A., \& Teichner, W. (2021). Feeling good: The future of the \$1.5 trillion wellness market. Available at: https://www.mckinsey.com/industries/consumer-packaged-goods/our-insights/feeling-good-the-future-of-the-1-5-trillion-wellness-market\#

[45] Hope, R. (2021). Sky News - Regular exercise may cut COVID-19 death risk by a third, major study finds. Available at: https://news.sky.com/story/covid-19regular-exercise-may-cut-covid-19-death-risk-by-a-third-major-study-finds-12281648.

[46] United Nations (2020). Recovering Better: Sport for Development and Peace advocacy brief by Division for Inclusive Social Development (DISD) under the Department of Economic and Social Affairs (DESA). Available at: https://www.un.org/development/desa/dspd/sport-development-peace.html

[47] Baker, J., Cobley, S., Schorer, J., \& Wattie, N. (2019). [Book] Routledge Handbook of Talent Identification and Development in Sport (1st Edition., Pages: 45076). London: Routledge. ISBN 9780367874216.

[48] Vaeyens R, Lenoir M, Williams AM, Philippaerts RM. Talent identification and development programmes in Sport: Current models and future directions. Sports Med. 2008;38(9):703-14. doi: 10.2165/00007256-200838090-00001. PMID: 18712939.

[49] Fernández-Aráoz, C., Green, C. and Nagel, G., 2021. The High Cost of Poor Succession Planning. Harvard Business Review (HBR). Available at: https://hbrorg.cdn.ampproject.org/c/s/hbr.org/amp/2021/05/the-high-cost-of-poor-succession-planning.

\section{AUTHORS}

First \& Correspondence Author - Hitesh Mangtani, MBA-Sports Management specializing in Talent/Athlete Identification, Recognition, Development \& Management, hiteshmangtani04@gmail.com. 